\title{
TV/Series
}

$10 \mid 2016$

Guerres en séries (II)

\section{L'art du stéréotype : la représentation des guerres de Religion dans la série Le Chevalier de Pardaillan de Josée Dayan (Antenne 2,1988)}

\section{Olivia Carpi}

\section{(2) OpenEdition}

Journals

Édition électronique

URL : http://journals.openedition.org/tvseries/1921

DOI : 10.4000/tvseries.1921

ISSN : 2266-0909

Éditeur

GRIC - Groupe de recherche Identités et Cultures

Référence électronique

Olivia Carpi, «L'art du stéréotype : la représentation des guerres de Religion dans la série Le Chevalier de Pardaillan de Josée Dayan (Antenne 2, 1988) », TV/Series [En ligne], $10 \mid$ 2016, mis en ligne le 01 décembre 2016, consulté le 10 décembre 2020. URL : http://journals.openedition.org/tvseries/1921 ; DOI : https://doi.org/10.4000/tvseries.1921

Ce document a été généré automatiquement le 10 décembre 2020.

\section{(i) $९$

TV/Series est mis à disposition selon les termes de la licence Creative Commons Attribution - Pas d'Utilisation Commerciale - Pas de Modification 4.0 International 


\title{
L'art du stéréotype : la représentation des guerres de Religion dans la série Le Chevalier de Pardaillan de Josée Dayan (Antenne 2, 1988)
}

\author{
Olivia Carpi
}

\section{Introduction}

1 Depuis le milieu des années 2000, la série historique est devenue ou redevenue une valeur sûre de la fiction télévisuelle, grâce à des coproductions qui allient l'efficacité américaine en termes de narration et de moyens mis en œuvre et la qualité esthétique et scientifique des period dramas britanniques. Beaucoup de ces séries historiques récentes s'aventurent dans les périodes reculées de l'histoire. Désormais, avec Rome (HBO, 2005-2007), Spartacus (Starz, 2010-2013), Vikings (History, depuis 2013), Marco Polo (Netflix, depuis 2014), les Tudors (Showtime, 2007-2010), Borgia (Canal+, 2011-2014), Les Borgias (Showtime, 2011-2013) ou Versailles (Canal+, depuis 2015), pour ne citer que les plus connues, c'est à l'Antiquité, au Moyen Âge, à la Renaissance ou au règne de Louis XIV que ces séries se consacrent, plus seulement à la période contemporaine et, en particulier, à la conquête de l'Ouest, aux deux guerres mondiales, à la guerre du Vietnam et à la guerre froide, qui ont fait les beaux jours des séries américaines de prime-time de la deuxième moitié du XXème siècle.

\section{La force dramatique des guerres de Religion}

Curieusement, les guerres de Religion ${ }^{1}$ françaises de la deuxième moitié du XVI ${ }^{\mathrm{e}}$ siècle n'ont, pour l'heure, pas retenu l'attention des producteurs de ce type de série. On peut 
s'en étonner dans la mesure où cette période recèle tous les ingrédients qui en font habituellement le succès : histoires d'amour, intrigues, trahisons mettant aux prises des personnages phares de l'histoire, entourés des légendes les plus folles et inscrites dans un contexte décadent, violent et sensuel ${ }^{2}$. Catherine de Médicis et ses fils Charles IX et Henri III, Henri de Navarre ou le duc Henri de Guise s'imposent comme des figures princières hautes en couleurs évoluant dans un univers sombre et sanguinaire. Au-delà de la fascination que pourrait exercer sur le public la geste de ces personnages, une série télévisée sur les guerres de Religion lui donnerait à n'en pas douter matière à réflexion.

3 Car c'est une époque à la fois cruelle et fondatrice, marquée par un affrontement fratricide entre Français - pour des raisons plus complexes, au demeurant, que le seul antagonisme confessionnel -, marqué entre autres par des crimes sans précédents tels que le massacre de la Saint-Barthélemy ou le régicide du dernier des Valois. Par ailleurs, la deuxième moitié du XVI ${ }^{\mathrm{e}}$ siècle est aussi un temps où on a tenté de trouver des réponses à des questions essentielles et toujours actuelles, telles que la place de la religion dans la société et son rapport avec l'État, ou la conception de la souveraineté, avec une vraie réflexion sur la tolérance et la conscience nationale ${ }^{3}$.

on s'intéresse à la représentation de cet épisode historique crucial dans une œuvre médiatique destinée au grand public, on pense tout d'abord au cinéma ${ }^{4}$. D'emblée, celui-ci s'est montré très prolixe sur le sujet, puisque l'un des tout premiers films jamais tournés en France, en 1897, est L'assassinat du duc de Guise de Georges Hatot, pour les frères Lumière ${ }^{5}$. Toutefois, l'étude de l'imaginaire audiovisuel des guerres de Religion n'a guère été menée jusqu'à présent, à la différence de l'Antiquité, qui a notamment bénéficié des travaux de Claude Aziza ${ }^{6}$.

C'est encore plus vrai pour les fictions de télévision portant sur les guerres de Religion. Celles-ci ne sont pas légion, à savoir une dizaine de téléfilms ${ }^{7}$. Les séries télévisées sur les guerres de Religion sont encore plus rares et négligées par les chercheurs, probablement à cause du manque de reconnaissance intellectuelle comme " objet culturel valide », dont elles ont longtemps pâti en France ${ }^{8}$. De plus, les recherches qui ont été engagées en sciences humaines sur les séries télévisées ces quinze dernières années concernent surtout des séries récentes et anglo-saxonnes, pour des raisons à la fois quantitatives et qualitatives 9 .

6 C'est cette lacune que nous souhaiterions contribuer à combler en faisant porter un regard d'historienne, amatrice de séries télévisées, sur l'une de ces productions françaises plutôt ancienne. On aurait pu retenir pour cette étude Jean de la Tour Miracle (ORTF, $1^{\mathrm{e}} \mathrm{ch}$., 1968), feuilleton en noir et blanc, en 10 épisodes de 22 minutes, adapté du roman de Joseph-Arthur de Gobineau, Le Prisonnier chanceux, réalisé par Jean-Paul Carrère, avec le tout jeune Patrick Dewaere dans le rôle titre. On aurait pu choisir aussi La Dame de Monsoreau (ORTF, $2^{\mathrm{e}}$ ch., 1971), un feuilleton en couleurs de sept épisodes de 55 minutes, créé par Claude Brûlé et réalisé par Yannick Andréi. Claude Brûlé est également partie prenante de la mini-série franco-allemande en 6 épisodes de 52 minutes, Le Roi qui vient du Sud/Heinrich, der gute König (TF1, 1979), adaptation du roman d'Heinrich Mann, frère aîné de Thomas. Les deux premières peuvent être considérées comme des séries culte, qui, selon les spécialistes, ont marqué l'apogée de la saga historique de soirée ${ }^{10}$, ce que confirment la possibilité d'en visionner des extraits sur Internet et l'existence d'une version restaurée en DVD et Blu-Ray ${ }^{11}$. 
7 Pourtant, c'est une autre série que nous avons sélectionnée, plus tardive, moins prestigieuse et beaucoup plus confidentielle, puisqu'elle n'est visible que dans les archives de l'Institut National de l'Audiovisuel ${ }^{12}$. Il s'agit de la série en 15 épisodes de 52 minutes, coproduite par Antenne 2 et la Société Française de Production, réalisée en 1986, diffusée le dimanche à $17 \mathrm{~h} 10$ du 3 janvier au 10 avril 1988 sur Antenne 2 et intitulée Le Chevalier de Pardaillan. Sur fond de lutte entre catholiques et protestants et de rivalités entre le duc de Guise, Henri de Navarre dit « Béarn » et Fausta, une descendante fictive de Lucrèce Borgia, pour l'accession au trône de France au moment où la dynastie des Valois s'éteint, la série retrace les aventures du héros éponyme, un jeune et sémillant gentilhomme gascon. Désargenté mais généreux, frondeur et redoutable bretteur, Pardaillan vole au secours des faibles et des innocents, toujours prêt à défendre sa belle, à châtier les méchants et à déjouer les plans diaboliques des grands de ce monde, aveuglés par leur ambition et leurs désirs amoureux.

\section{Michel Zévaco, épigone avoué d'Alexandre Dumas}

Indépendamment du sujet et de la nature de l'œuvre, le choix de cette série s'explique par diverses raisons, qui ne tiennent pas seulement à la nostalgie d'une jeunesse bercée par les romans de la Bibliothèque verte et la télévision, ou à un possible esprit de contradiction, aiguisé par les critiques très sévères dont Le Chevalier de Pardaillan a fait l'objet ${ }^{13}$. Cette série mérite l'attention d'abord parce qu'une fois n'est pas coutume, ce n'est pas une adaptation d'un roman d'Alexandre Dumas, à la différence de nombreuses autres séries historiques françaises, que ce soient Le Chevalier de Maison rouge (RTF, 1963), D'Artagnan (ORTF, $2^{\mathrm{e}}$ ch., 1969-1970), Joseph Balsamo (ORTF, $1^{\mathrm{e}}$ ch., 1973), Le Comte de Monte Cristo (FR3, 1979-1980) ou La Comtesse de Charny $(\mathrm{TF} 1,1989)^{14}$. Il s'agit de l'adaptation des quatre premiers tomes (Les Pardaillan, L'Épopée d'amour, La Fausta, Fausta vaincue) du roman fleuve, qui en compte dix, de Michel Zévaco, Les Pardaillan ${ }^{15}$. Bien qu'il soit aujourd'hui quelque peu tombé dans un oubli dont s'efforcent de le faire sortir des passionnés et des chercheurs en littérature, ce contemporain de Maurice Leblanc, Gaston Leroux, Pierre Souvestre et Marcel Alain, pères d'Arsène Lupin, de Rouletabille et de Fantômas, apparaît comme l'un des maîtres du roman populaire, et plus précisément, du roman de cape et d'épée ${ }^{16}$. Cependant, tout comme Ponson du Terrail et Paul Féval fils, avec Rocambole et Lagardère, l'écrivain est en quelque sorte rejeté dans l'ombre par la notoriété des personnages qu'il a créés et qui ont accédé à une existence autonome en prenant vie à l'écran ${ }^{17}$.

De fait, l'adaptation des Pardaillan en série télévisée ne doit rien au hasard. La première explication gît dans la nature même de l'œuvre romanesque, qui est, à l'origine, un feuilleton, publié dans La Petite République socialiste puis dans Le Matin de 1905 à 1918, avant d'être édité, entre 1907 et 1913, par Arthème Fayard, dans la collection «Le Livre populaire ». Ces ouvrages bon marché, ornés des superbes illustrations de Gino Starace, « s'affichaient aux devantures des kiosques de la Belle époque et (...), fonctionnant comme un cinéma imprimé, ont fortement contribué aux succès de ces romans ${ }^{18}$. " A priori, il semble relativement commode de transposer un feuilleton littéraire en feuilleton télévisé, surtout pour un scénariste aussi aguerri que Jean Chatenet, collaborateur de Jean Cosmos sur Le 16 à Kerbriant (ORTF, $1^{\mathrm{e}}$ ch., 1971) et Ardéchois, coeur fidèle (ORTF, $2^{\mathrm{e}} \mathrm{ch}$., 1974), d'André Castelot sur Le Comte de Monte-Cristo de Denys de la Patellière (FR3, 
1979-1980) et seul auteur pour Des Grives aux loups (Antenne 2, 1984), d'après le roman de Claude Michelet.

10 L'adaptation est encore facilitée par le fait que, tout comme Dumas, Zévaco pratique une écriture très théâtrale. En outre, Zévaco était un passionné du $7^{\mathrm{e}}$ art, qui a lui-même réalisé un film, Déchéance, projeté après sa mort, en 1918, ce qui explique que « le roman ressemble aussi parfois au script d'un scénario, dans son découpage, ainsi que dans la volonté de mettre en scène, de cadrer les personnages, de noter les mouvements, de varier les perspectives ${ }^{19}$. " Enfin, il faut savoir que Michel Zévaco n'est pas un simple auteur de romans d'aventures, mais un ancien professeur de lettres, très cultivé, épigone avoué de Dumas. Zévaco fut également un homme engagé, un journaliste à la plume acérée, « qui a su mêler le dépaysement et l'insouciance du roman de cape et d'épée à des préoccupations politiques qui percent à travers la légèreté du récit ${ }^{20}$. »

\section{Le feuilleton de cape et d'épée, genre populaire}

11 Les romans de Zévaco offrent donc une belle matière pour une production à grand spectacle, riche en émotions et porteuse de leçons, ce qui explique qu'ils aient fait l'objet de nombreuses adaptations, dès 1914, avec un des derniers films réalisés par Georges Hatot $^{21}$ et, surtout, dans les années 1960, à la grande époque du « western à la française », inspiré d'Hollywood et dont le public national était très friand ${ }^{22}$. On retrouve les grandes stars du genre, Jean Marais et Jean-Claude Barray, au générique des trois adaptations cinématographiques des romans de Michel Zévaco, à savoir Le Capitan d'André Hunebelle en 1960, Le Chevalier de Pardaillan et Hardi ! Pardaillan de Bernard Borderie, en 1962 et 1963 23. Par conséquent, bien que les critiques parlent d'« un cinéma plat, facile, qui évite l'ennui par la constante agitation à l'écran, un festival de bagarres, d'escrime, d'acrobaties, de voltige à cheval et de traquenards, dans l'esprit des serials d'autrefois ${ }^{24}$ ", Les Pardaillan peuvent être considérés comme une valeur sûre du divertissement populaire.

12 Le Chevalier de Pardaillan se distingue également comme la première série intégralement tournée par Josée Dayan, qui, après Marion Sarraut, s'est imposée au tournant des années 1990-2000 comme la reine de la série romanesque, littéraire et historique, avec La Rivière Espérance (France 2, 1995), Le Comte de Monte Cristo (TF1, 1998), Les Misérables (TF1, 2000), Les Liaisons dangereuses (TF1, 2003), et Les Rois maudits (France 2, 2005). On peut se demander si le style qu'elle a imposé dans ces œuvres postérieures était déjà présent dans cette série bien qu'il s'agisse d'une commande à budget limité, " où le rôle clé est celui du scénariste et non du réalisateur, dépossédé d'un statut de créateur [et dont le tournage est confié à] des metteurs en images du secteur privé, acceptant les conditions de travail et les exigences de rendement imposées par de faibles budgets ${ }^{25}$. »

En tant que produit télévisuel, la série Le Chevalier de Pardaillan n'a rien d'original et c'est en cela aussi qu'elle est intéressante, parce qu'emblématique d'un genre télévisuel hexagonal des plus classiques, ainsi que d'un paysage audiovisuel particulier, les années qui ont immédiatement suivi la privatisation de TF1. Il s'agit d'abord d'un feuilleton, autrement dit une fiction avec des épisodes à suivre ${ }^{26}$, genre longtemps cantonné aux programmes de journée outre-Atlantique, parce que jugé trop difficile à rejoindre en cours de route par des téléspectateurs de soirée moins assidus et trop risqué pour les grands annonceurs ${ }^{27}$. En France, la finalité de ces feuilletons est de remplir des grilles de programmes dont le volume n'a cessé d'augmenter, en raison de la création d'une 
deuxième, puis d'une troisième chaîne, en 1964 et en 1973, et de l'allongement du temps d'antenne, spécialement les créneaux de l'après-midi et ceux qui précèdent ou qui suivent le journal télévisé. L'objectif est de fidéliser un public familial en lui offrant des rendezvous réguliers, hebdomadaires ou quotidiens, le samedi, le dimanche et le jeudi, avec des formats d'émissions de 13 ou 15, 28, 52 ou 55 minutes.

\section{De la saga de prestige à la spaderie} années 1970, servies par l'apparition de l'image en couleurs en 1967 et l'autorisation de la publicité à l'antenne en 1971, générant pour les chaînes publiques des ressources plus importantes à investir dans leurs productions ${ }^{28}$. Initialement tournés en $16 \mathrm{~mm}$ par des réalisateurs de talent, ces programmes sont reconnaissables à l'adaptation de romans populaires du $\mathrm{XIX}^{\mathrm{e}}$ siècle ou du début $\mathrm{XX}^{\mathrm{e}}$, au récit des amours impossibles ou contrariées de héros jeunes et beaux, confrontés aux machinations de puissants sans scrupules, au résumé de l'intrigue en voix off au début de chaque épisode, à la qualité d'écriture du scénario et des dialogues, à l'excellence du jeu des comédiens, à la magnificence des décors et des costumes, à la fréquence des scènes d'action, réglées à la perfection (duels à l'épée ou courses-poursuites à cheval) et, enfin, à une bande musicale soignée ${ }^{29}$. Le Chevalier de Pardaillan devrait à première vue s'inscrire dans cette lignée de programmes d'exception, nécessitant de gros moyens financiers.

Mais dans les années 1980, l'univers de la télévision est devenu extrêmement concurrentiel, à cause de l'apparition d'une chaîne privée cryptée en 1984, Canal Plus, et surtout de la privatisation, en 1986, de la première chaîne publique, TF1, puis de la création de deux chaînes privées hertziennes généralistes, La Cinq et M6 en 1986 et 1987. Les temps d'antenne s'allongent encore, les séries américaines, dont Dallas, plus présentes que jamais sur les écrans français, accusent le côté désuet des séries hexagonales. Cellesci tentent de s'adapter à ce nouvel environnement, principalement en conservant un type de produit auquel le public est habitué et qu'il apprécie, dans le cadre d'une «télévision de la demande ", régie par l'Audimat ${ }^{30}$.

C'est pourquoi, même si leur volume diminue notablement entre 1986 et 1989 - lorsque la commémoration du bicentenaire de la Révolution française relance brièvement la fiction historique sans en entraver le déclin - Antenne 2 continue de diffuser des feuilletons historiques $^{31}$. Cependant, elle le fait désormais à moindres frais, étant donné que les précédentes productions ont coûté des sommes astronomiques, impossibles à amortir. Avec la perte de son monopole et la popularité croissante de TF1, le but n'est plus, dorénavant, de créer l'événement en prime time, mais seulement de retenir le public sur la chaîne, aux heures de moins grande audience ${ }^{32}$. On tourne donc des feuilletons en vidéo et en studio, "sur commande de la chaîne auprès de la SFP d'un produit clé en main d'un rapport qualité-prix convenable », pour un coût de l'ordre d'un million de francs l'heure pour une quinzaine ou une vingtaine d'heures de programme, réalisés en moins de cinquante jours, contre plus de 20 millions pour les mini-séries de soirée de 5 à 8 épisodes, produites avant la privatisation, telles que L'Epingle noire (Antenne 2, 1982), Fabien de la Drôme (Antenne 2, 1983) ou Félicien Grevèche (Antenne 2, 1986) ${ }^{33}$.

Tout comme Marianne, une étoile pour Napoléon (Antenne 2, 1983), Catherine (Antenne 2, 1986), Le Gerfaut (TF1, 1987) et La Comtesse de Charny (TF1, 1989), Le Chevalier de Pardaillan est typique de ces feuilletons de durée et de qualité intermédiaires des années 1980, qui

TV/Series, 10 | 2016 
supplantent les mini-séries en récession (à peine plus de $2 \%$ de la fiction diffusée en 1989) et qui relèvent de la "spaderie ». On entend par là un type de production lancé à la fin des années 1970 par Henri Spade, alors à la tête de la SFP, confrontée à un lourd déficit. D'abord appliqué aux feuilletons quotidiens bas de gamme de début d'après-midi, ce procédé se caractérise par « une structure de décor unique rapidement transformable, un tournage vidéo avec lumière axiale prévue pour plusieurs caméras, la prédominance des dialogues sur l'action, le recours à des comédiens issus du théâtre, capables de jouer en quasi continu ${ }^{34}$.»

Sur ces feuilletons, le jugement des spécialistes est sévère : «travail bâclé, photographie laide et glacée, pauvreté des décors, jeu approximatif des comédiens, duels réduits à quelques simples coups d'épée, manque de continuité entre les séquences qui sont autant de sketches montés les uns à la suite des autres ${ }^{35}$. » Dans le cas du Chevalier de Pardaillan, on parle même de «massacre ${ }^{36}$. » C'est oublier, tout de même, que la bande musicale est de Robert Vigier, qui a travaillé avec Vladimir Cosma, que les scènes de combat ont été chorégraphiées par Claude Carliez, qui, dans les années 1960-80, a coordonné les cascades de nombreux films de cape et d'épée et de la plupart des films avec Jean Marais, Jean-Paul Belmondo, Louis de Funès ou Alain Delon. C'est occulter aussi que la distribution accueille des comédiens expérimentés, voire de renom, tels Patrick Bouchitey dans le rôle-titre, Philippe Clay (Pardaillan père), inoubliable interprète de la chanson des Brigades du Tigre et qui a joué pour Jean Renoir, Dominique Blanchar (Catherine de Médicis), mise en scène par Louis Jouvet et ayant incarné la première l'épouse du commissaire Maigret, François Mathouret (Anjou/Henri III), un habitué des fictions télé de prestige, ou encore Pascal Greggory (Angoulême), acteur à l'époque des films de Rohmer et de Téchiné mais surtout de théâtre, ainsi que beaucoup d'autres comédiens formés à la Comédie française.

\section{Un récit politiquement correct des guerres de Religion}

19 Ainsi, en dépit ou peut-être à cause de l'absence, dans cette série, des "ambitions esthétiquement et culturellement élevées » qui auraient fait la valeur de ses devancières, nous nous proposons tout de même de la soumettre à une analyse critique de la vision des guerres de Religion qu'elle propose ${ }^{37}$. L'objectif sera de mettre en lumière la relation que le contenu de la série entretient avec le passé, en particulier la présentification, la construction et la perception d'une période sinistrement connotée dans la mémoire collective $^{38}$. À bien des égards, appliquer un tel questionnement au Chevalier de Pardaillan relève de la gageure. D'une part, on a affaire à une «feintise (...) qui présente au spectateur un univers qui n'est pas le réel et qui donne ouvertement cet univers comme inventée ${ }^{39}$. » Car, si les feuilletons restent, jusqu'à la fin des années 1980, le genre privilégié de l'histoire à la télévision, «c'est la forme la plus éloignée de toute préoccupation de fidélité à l'histoire ${ }^{40}$. En outre, cette fiction télévisée est elle-même tirée d'un roman de cape et d'épée, encore moins soucieux de la véracité historique que le roman historique classique, déjà qualifié par Diderot de "mauvais genre », accusé de "tromper l'ignorant et de dégoûter l'homme instruit ${ }^{41}$.» C'est d'ailleurs pourquoi le linguiste Jacques Jarry range Les Pardaillan de Zévaco au rang des "romans de pacotille", qui n'apporteraient rien à la connaissance des guerres de Religion, contrairement à ceux de Dumas, de Prosper Mérimée, d'Ernest Pérochon et de Robert Merle ${ }^{42}$.

D'autre part, avec ce feuilleton, on se confronte à « une forme consubstantiellement idéologique et économique ${ }^{43}$ ", obéissant à « une logique de la satisfaction ${ }^{44}$ » du public, 
qu'il ne faut pas heurter, ni rebuter, ce qui prévient toute audace de la part de ses créateurs, sachant que l'une des principales clefs du succès de ces feuilletons réside dans « le plaisir né de la répétition ${ }^{45}$.» Enfin, il faut rappeler que la série n'est passée à l'écran que pendant trois mois et demi, ce qui la rendait peu susceptible de marquer les esprits en profondeur et qu'un volume total de 13 heures seulement laisse augurer une certaine superficialité du propos. Pour ses artisans, cela n'était pas un problème puisque ce programme vise prioritairement, quoique pas exclusivement, le divertissement, a fortiori dans les années 1980, où la télévision française n'est plus «l'école parallèle " qu'elle prétendait être trente ans plus tôt, ni même la télévision des historiens, comme cela a été le cas pendant la décennie précédente ${ }^{46}$.

21 Cela étant, nous tâcherons de montrer que cette série éminemment patrimoniale, dans la facture comme dans le contenu, est triplement le résultat d'un art du stéréotype, d'abord parce qu'elle se conforme à un modèle bien établi, celui de la fiction historique, à la fois littéraire et télévisuelle, dont l'objet n'est pas tant la restitution fidèle du passé que la création d'un monde culturellement exotique et aussi crédible que possible - dans la limite des ressources matérielles et scientifiques dont ses artisans disposent et en fonction des normes stylistiques auxquelles ils se réfèrent ${ }^{47}$. Puis, nous verrons que le contenu historique de la série se ramène à une série de clichés, relatifs aux personnages comme aux événements et dont on peut établir la genèse et la longévité dans l'imaginaire collectif des Français. Enfin, nous établirons que, loin de la vacuité de message qu'on reproche souvent à ce genre d'œuvre, à travers l'évocation d'une mythologie nationale, cette série télévisée offre bien une lecture qu'on pourrait qualifier de "politiquement correcte » des guerres de Religion dans la France des années $1980^{48}$.

\section{La recréation d'un monde}

\section{De multiples erreurs historiques..}

Un des principaux reproches qui est fait par les spécialistes du genre à la série Le Chevalier de Pardaillan réside dans ses nombreux anachronismes. Ainsi, «à la table des conjurés de Guise, un des comploteurs est assis sur un coquet guéridon Napoléon III et Pardaillan père regagne le château familial avec, pour bagages, deux sacoches de vélosolex ${ }^{49}$.» On pourrait aisément multiplier les remarques du même acabit et pointer des erreurs effectivement assez gênantes du point de vue de la véracité historique dans l'accoutrement des personnages ou la manière dont ils s'expriment. Par exemple, dans la scène de son assassinat, le duc de Guise, chef de la Ligue, une association de catholiques radicaux, porte en travers de la poitrine une écharpe blanche. 
Figure 1 : Le duc de Guise (Didier Flamand) dans Le Chevalier de Pardaillan (épisode 14)

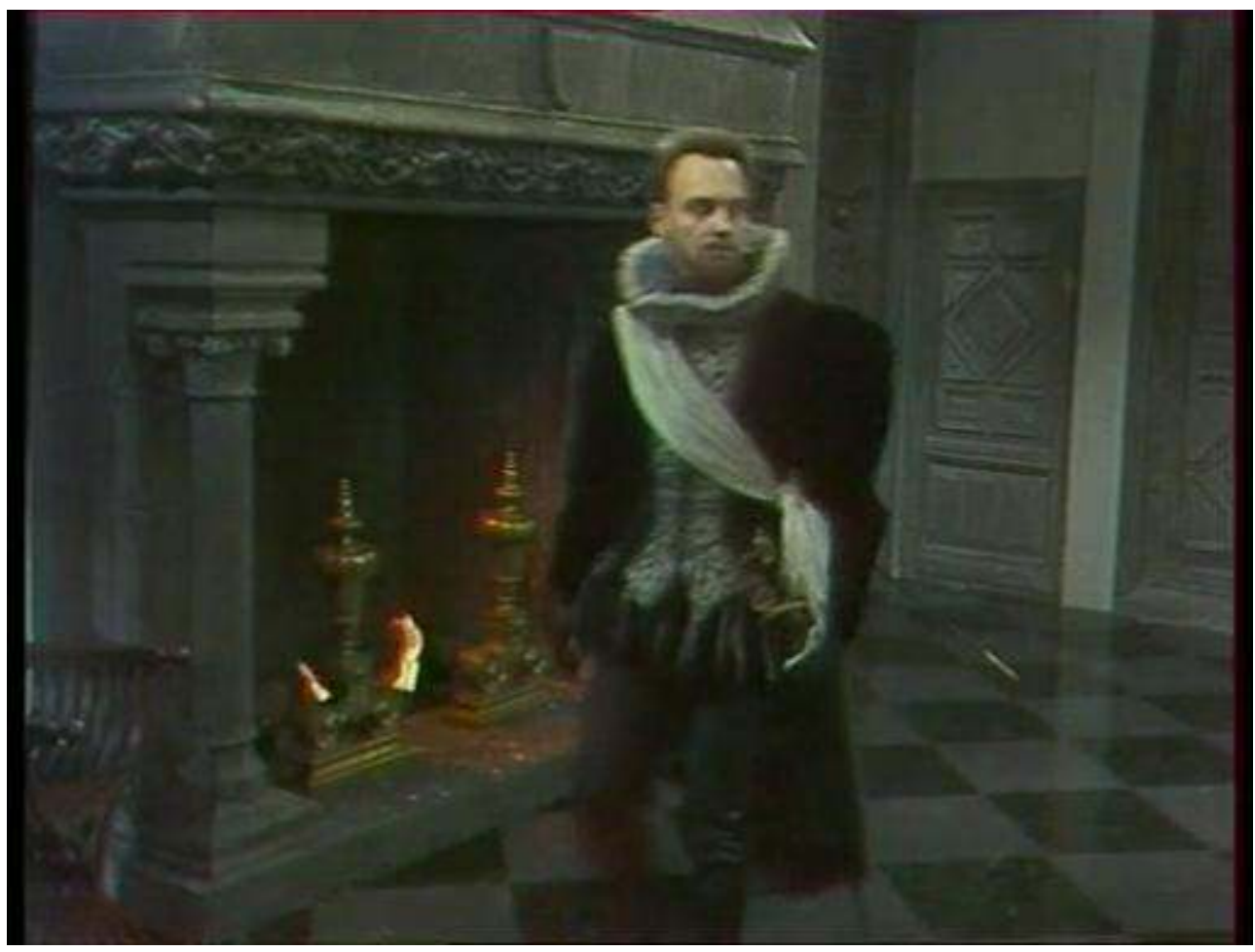

Or c'est à l'époque le signe de ralliement des chefs de guerre huguenots, devenue un emblème de la fonction de commandement militaire seulement après l'accession au trône d'Henri de Navarre, en 1589. Sans doute a-t-on confondu l'écharpe avec le ruban bleu de l'ordre du Saint-Esprit que le prince avait effectivement reçu d'Henri III et qu'on le voit porter sur ses portraits.

Fig.2 : Portrait anonyme d'Henri ler de Lorraine, duc de Guise (Musée de Condé, Chantilly, non daté)

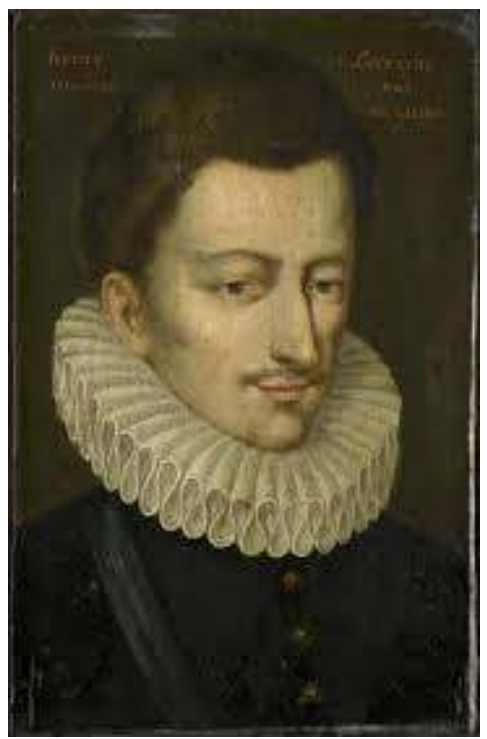

De même, dans la série, Catherine de Médicis qualifie les protestants de «parpaillots », qui n'est pas un terme usité au XVI ${ }^{\mathrm{e}}$ siècle, où on les désigne comme « ceux de la nouvelle opinion » ou « de la religion prétendue réformée », voire comme les « hérétiques » pour 
mieux les stigmatiser. Le mot « parpaillot » n'est utilisé qu'au XIXe siècle, notamment par les auteurs de romans historiques comme Zola, Dumas, et Zévaco après eux. Cette incongruité pour l'historien tient donc à la fidélité du scénariste et dialoguiste envers le roman, qui explique également, en grande partie, la piètre qualité globale de la reconstitution historique dans la série.

L'une des principales caractéristiques de la fiction historique, littéraire ou télévisée est, en effet, de plonger le lecteur ou le spectateur dans "un cadre temporel excentrique ", tout en rendant ce passé vraisemblable grâce à la précision des indications chronologiques, topographiques, onomastiques, de même que par le langage, l'allure et le costume des personnages historiques ${ }^{50}$. Dans Le Chevalier de Pardaillan, il faut l'avouer, les résultats de cette entreprise s'avèrent plutôt limités.

Ce média ne peut être affiché ici. Veuillez vous reporter à l'édition en ligne http:// journals.openedition.org/tvseries/1921

Pour se situer dans le temps, on ne dispose que de deux dates. La première, 1572, est inscrite au bas de l'écran au début de l'épisode 1. On ne précise pas que c'est l'année de la Saint-Barthélemy et le feuilleton situe la conclusion de la paix de Saint-Germain entre les catholiques et les protestants cette même année, alors qu'elle a été signée deux ans plus tôt, le 8 août 1570. De même, au début de cet épisode, Catherine de Médicis se plaint des machinations du duc de Guise, alors qu'en réalité il n'est pas encore un personnage politique de premier plan. Par ailleurs, en 1572, la dynastie des Valois ne semble pas du tout en danger : le roi Charles IX est déjà père d'une petite fille, ce qui permet à son frère Henri de monter en confiance sur le trône de Pologne.

La deuxième date, 1588, apparaît de la même façon à la $40^{\mathrm{e}}$ minute de l'épisode 8 , juste après la mort de Charles IX. Cette ellipse temporelle est assez mal négociée : on a donné l'impression aux téléspectateurs que Charles IX mourrait juste après la Saint-Barthélemy (alors que c'est deux ans plus tard, que son frère Henri était présent alors qu'il se trouvait en Pologne, et que la Ligue catholique était déjà active alors qu'elle n'a été créée qu'en $\left.1576^{51}\right)$.

De nombreuses libertés sont prises avec les dates et les lieux, comme avec les noms propres. Ainsi, le héros, Pardaillan, porte le même patronyme qu'un petit seigneur du Lot-et-Garonne, qui aurait fait partie de l'entourage de Navarre, mais qui est mort lors de la Saint-Barthélemy ${ }^{52}$. Le comte de Marillac, titre que porte le bâtard fictif de Catherine de Médicis et de son astrologue Ruggieri, élevé par Jeanne d'Albret, était celui d'un noble né en 1572, qui a servi Henri IV et Richelieu et qui a été exécuté en Place de Grève en 1632 pour trahison. Ou bien encore, il y a bien eu un cardinal Farnèse, sauf qu'il ne s'appelait pas Jean, mais Alexandre et qu'il n'a séjourné en France que sous Henri II, avant de regagner Rome dès 1554.

29 À l'instar de Bouvard et Pécuchet, qui, dans le roman de Flaubert, s'emploient à traquer les inexactitudes qui émaillent les œuvres de Scott et de Dumas, on pourrait s'amuser à faire la liste de toutes les erreurs présentes dans la série Le Chevalier de Pardaillan ${ }^{53}$. Ce serait méconnaître totalement la nature même de l'œuvre littéraire dont la série télévisée est l'adaptation. L'objectif de ce récit n'est en effet pas d'être authentique, mais de créer l'illusion d'un monde temporellement et culturellement lointain que l'on souhaite rendre vivant et accessible au public. 


\section{...au service du pittoresque et du romanesque} lieux et des personnages. Dans la série, par souci d'économie, les décors ne sont pas nombreux et consistent essentiellement en intérieurs, chichement meublés, décorés dans un style censé correspondre à leur fonction. Par exemple, au début de l'épisode 1, Paris n'est montré que sous la forme d'une gravure du début du XVII siècle, non commentée, seulement agrémentée de cette légende « Paris, 1572 » (épisode 1). Il n'est pas certain que le néophyte y reconnaisse la Seine, le Louvre, le palais et le jardin des Tuileries. De la ville, on ne voit ensuite que quelques rues, consistant en un passage entre deux parois figurant des murs de pierre et percées d'ouvertures en guise de portes. La Bastille et la prison du Temple, où le héros est enfermé, se réduisent à une cellule au sol jonché de paille et à un mur où sont fixées des chaînes, le couvent où vivent les catholiques extrémistes à une cellule très similaire à cette geôle et l'auberge où réside le héros à une salle, analogue à celle d'un autre tripot visible plus tard dans la série.

Le palais royal se résume à un couloir, le cabinet de la reine, la salle d'armes et la chambre de Charles IX. La décoration évoque incontestablement la Renaissance, et encore plus l'idée que l'on pouvait s'en faire au XIX ${ }^{54}$ siècle: un sol de marbre en damier, des boiseries sculptées aux murs, des fenêtres à croisillons, des lustres à pendeloques au plafond, des colonnes ou des piliers, des bustes et des statuettes antiques dans des niches ou sur des consoles, des portraits peints et des miroirs aux murs, etc. (épisodes 1, 4 et 7).

Figure 3 : Le cabinet de la reine dans Le Chevalier de Pardaillan (épisode 14)

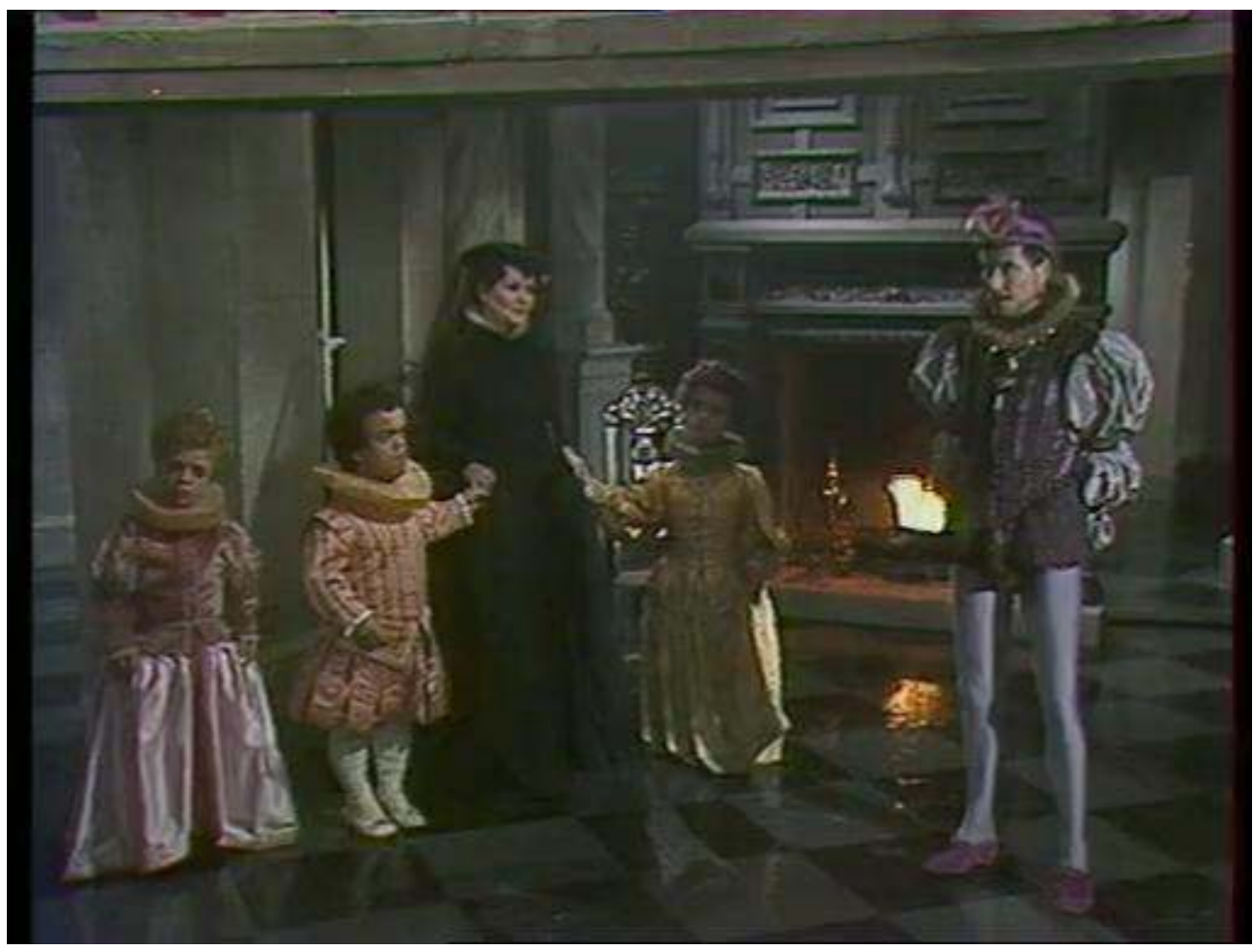

Tout cela est conforme aux rares tableaux du $\mathrm{XVI}^{\mathrm{e}}$ siècle qui montrent des scènes de cour au temps des derniers Valois (cf. par exemple Bal à la cour d'Henri III, attribué à Hiéronymus Francken, Paris, Musée du Louvre, après 1583) et à la pièce appelée studiolo, 
attenante à la chambre de Catherine de Médicis au château de Blois, seul exemple conservé dans son état initial de cabinet royal de la Renaissance française.

Figure 4 : Le studiolo du château de Blois

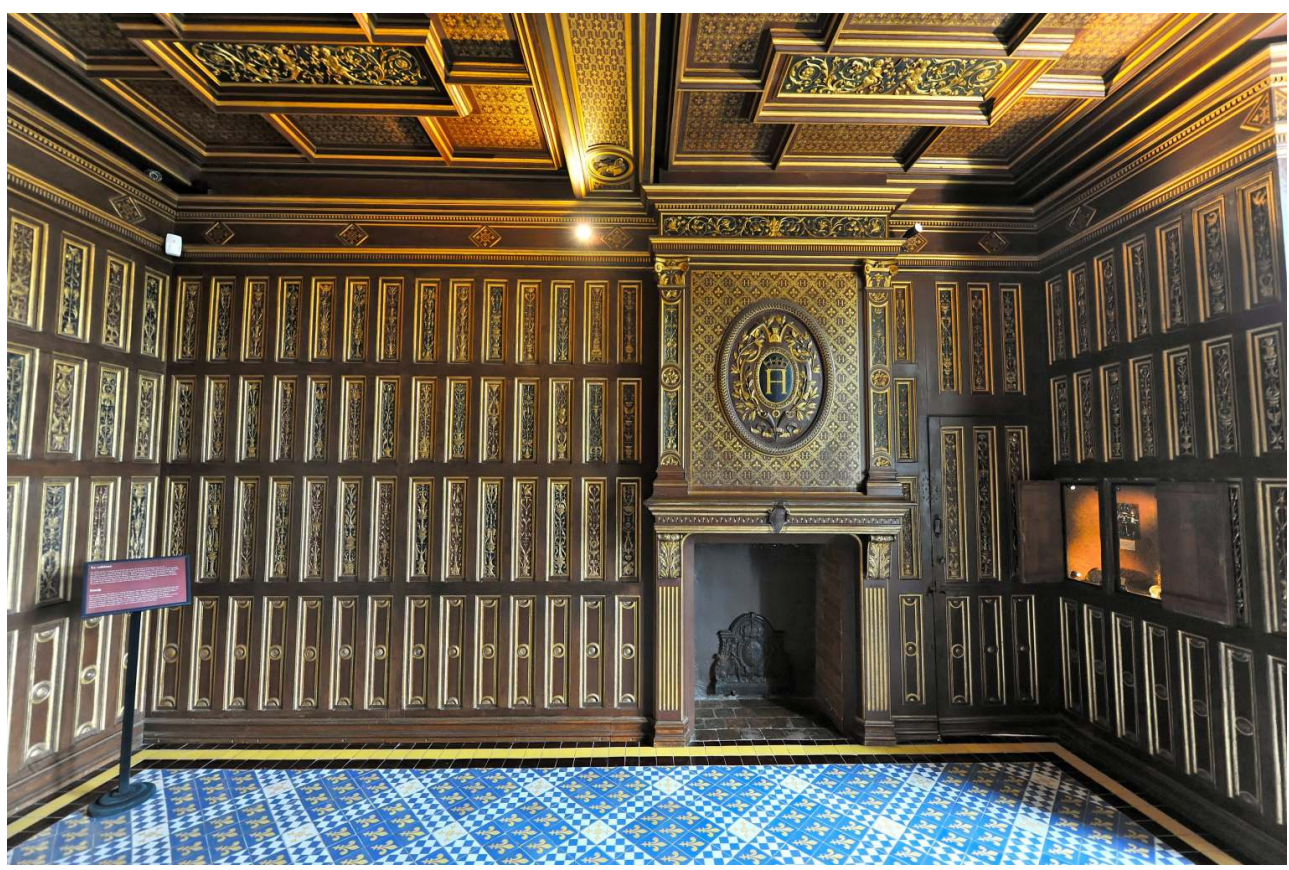

Les extérieurs sont rares. La Saint-Barthélemy, qui aurait réclamé nombre de figurants et reconstitution des rues de Paris, est surtout abordée sous l'angle des conspirations ourdies par les uns et par les autres, dans l'intimité de leur résidence. Hors les murs, on voit surtout des chevauchées, comme celle de Pardaillan au générique, des arrivées ou des entrevues dans des cours de châteaux, des déambulations dans des rues de vieille ville ou en bord de fleuve, des bagarres de rues ou au beau milieu d'un champ de verdure. Ces scènes ont été tournées à Beaune, Château-Neuf-en-Auxois, Chinon, Tours, MontceauEcharnant, Noyers-sur-Serein, dans des endroits ayant conservé leur cachet historique, situés pas très loin de Paris et qui ne posaient sans doute pas de gros problèmes d'autorisation de tournage, à la différence de monuments historiques comme le château de Blois ${ }^{55}$.

Néanmoins, dans la série, les décors ne sont jamais filmés pour eux-mêmes : ils servent avant tout de cadre aux personnages, sur lesquels la caméra se focalise, avec force gros plans et plans moyens. La ressemblance des comédiens avec les personnages historiques réels est à peu près assurée par le biais de la corpulence, de la coiffure, du maquillage et des costumes (cf. figure 3). Cependant, l'extravagant plastron de cuir clouté du duc de Guise ou le décolleté vertigineux à ailes de chauve-souris de la Fausta n'ont pas grand chose à voir avec les tenues aristocratiques du temps. Ils visent surtout à souligner la psychologie de ces personnages inquiétants, qui misent autant sur leur séduction physique que sur la violence pour parvenir à leurs fins. D'ailleurs, les comédiens ne changent quasiment jamais de costumes, qui servent à les identifier et à les caractériser aux yeux du spectateur qui les retrouve d'une semaine à l'autre. 
Figure 5 : Fausta (épisode 9)

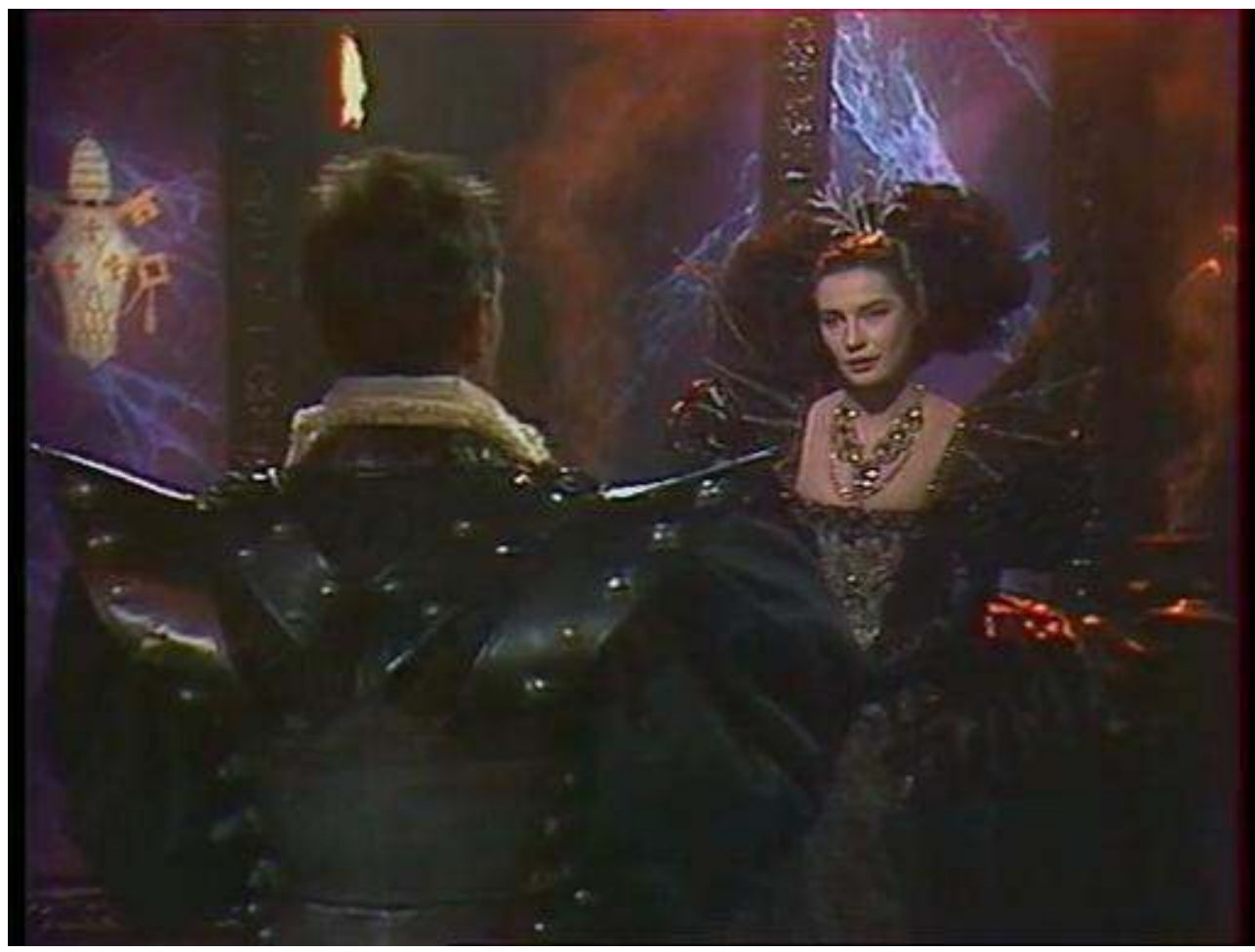

En outre, si pour les plus célèbres, comme Catherine de Médicis, Navarre, Guise, l'aspect des comédiens s'apparente fortement à l'iconographie officielle de ces personnages historiques, on remarque un décalage chronologique évident. Navarre et Guise sont interprétés par des hommes mûrs tout au long de la série, alors qu'ils n'avaient qu'une vingtaine d'années en 1572. Probablement ne disposait-on pas du budget pour rajeunir ou vieillir les comédiens ou bien n'a-t-on pas souhaité en engager deux différents pour camper le même personnage à deux âges successifs de sa vie.

Figure 6: Dominique Blanchar en Catherine de Médicis (épisode 1) et un portrait de la reine réalisé par l'atelier de François de Clouet vers 1570 (Paris, Musée Carnavalet)
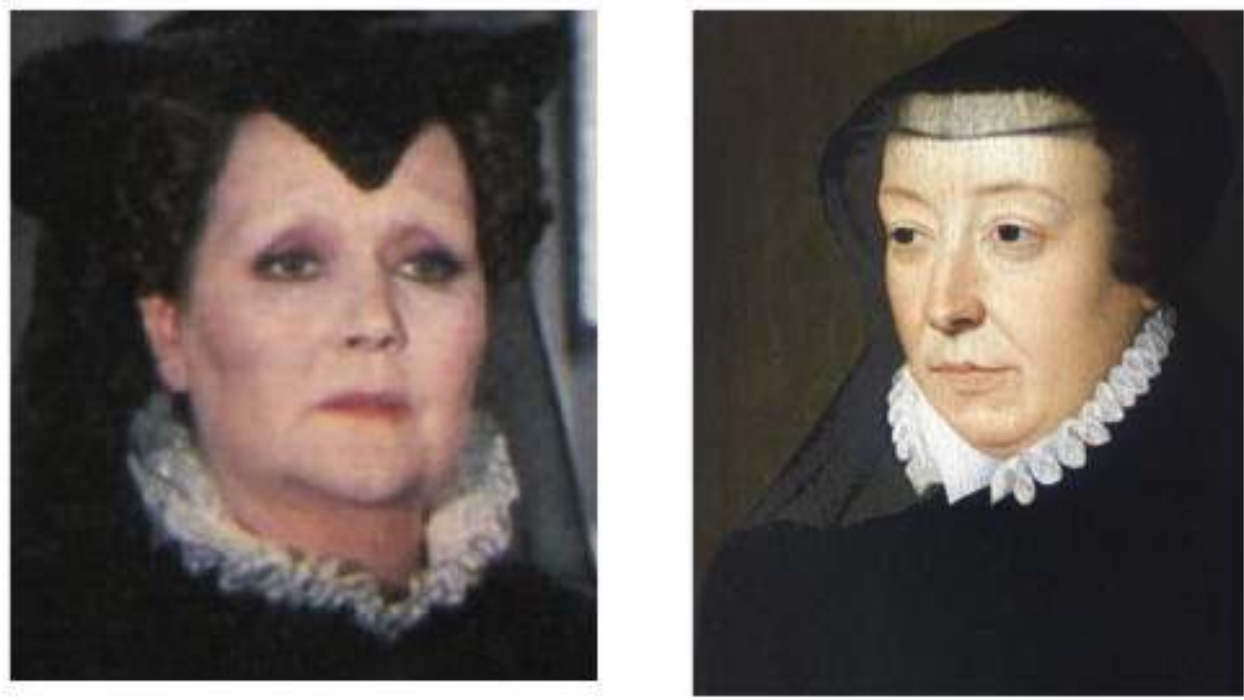
Figure 7 : Emmanuel Dechartre dans le rôle d'Henri de Navarre (épisode 6) et Didier Flamand dans le rôle du duc de Guise (épisode 8 ), face aux portraits contemporains des personnages qu'ils incarnent (vers 1570 puis vers 1590)
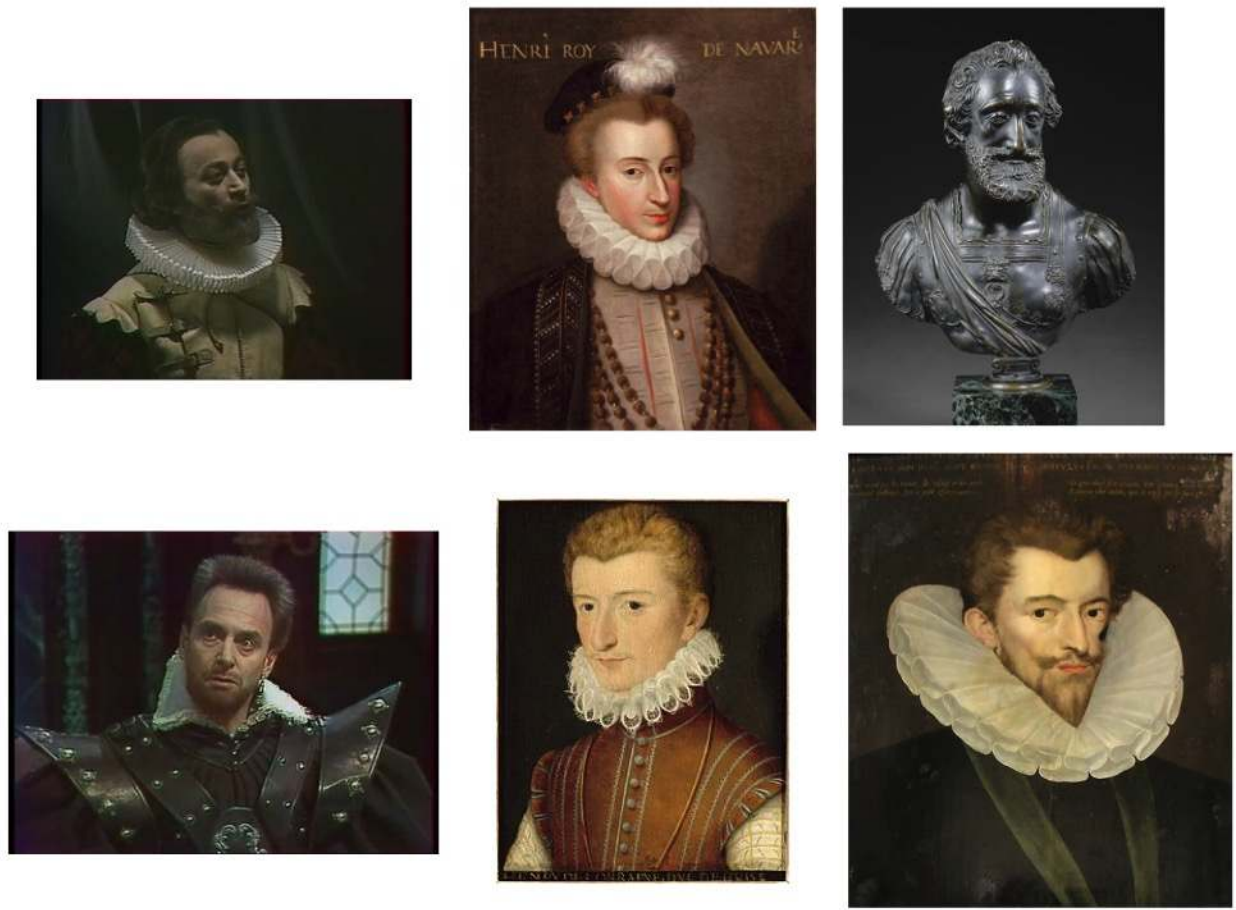

L'illusion est donc loin d'être totale et c'est encore pire quand les personnages parlent, à cause d'effets oratoires trop marqués, de la récurrence de mots archaïques comme olibrius ou bellitre, et d'interjections telles que diantre, mortdiable/mortbleu ou palsambleu. Sans oublier les vai vai, basta, et capito dont Catherine de Médicis ponctue ses phrases, tout en roulant outrageusement les « $\mathrm{r}$ » et en étirant à l'envi ses syllabes finales, ce qui frise vraiment le ridicule quand elle dit, par exemple, «Jeanne d'Albrèteee » pour Jeanne d'Albret, mère d'Henri de Navarre (épisode 4).

Ce média ne peut être affiché ici. Veuillez vous reporter à l'édition en ligne http:// journals.openedition.org/tvseries/1921

\section{Une violence hors champ}

Tout cela fleure très fort l'artifice, qui est encore plus flagrant dans les scènes d'affrontement, de crime ou de trépas, quand elles ne sont pas tout bonnement escamotées, tout comme les scènes festives qu'on se serait attendu à voir à l'occasion du mariage de Béarn et de Marguerite Valois, sur lequel la série fait l'impasse. Le coup de pistolet de Charles IX contre Condé (épisode 7), les coups d'épée ou de poignard qui sont donnés à Guise ou Henri III (figure 8) ou l'agonie de Charles IX ou de Catherine de Médicis prêtent plus à sourire qu'à frissonner de peur. 
Figure 8 : Le meurtre du duc de Guise (épisode 14)

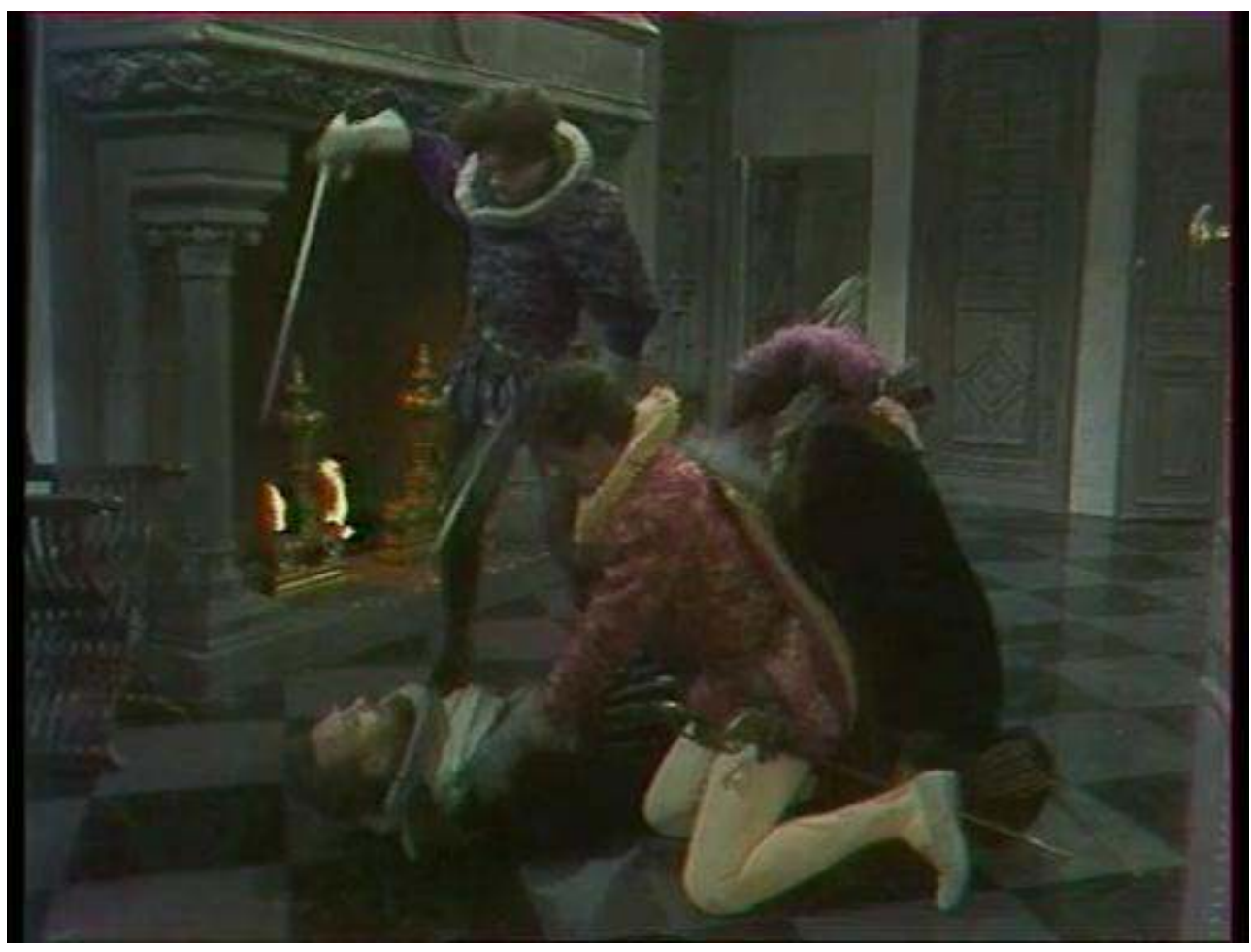

De même, aucune scène ne montre l'attentat manqué contre Coligny, victime d'un coup d'arquebuse : on entend seulement une détonation (épisode 6). On n'assiste pas non plus pas plus à sa décapitation, après sa défenestration, lors de la Saint Barthélemy : on voit seulement l'exécuteur, Behme, brandir un sac censé contenir la tête du malheureux (épisode 7). Dans la deuxième partie de la série, les barricades parisiennes du 12 mai 1588 qui ont contraint Henri III à fuir la capitale, sont mentionnées en une seule phrase du roi à la $42^{\mathrm{e}}$ minute de l'épisode 8 . On ne voit pas non plus l'arrestation du cardinal de Guise et des autres chefs ligueurs sur l'ordre d'Henri III, on entend seulement des cris en arrièrefond (épisode 15). Le camp de Saint-Cloud, où l'armée royale, alliée à celle de Béarn, s'est installée pour faire le siège de Paris aux mains des ligueurs, se résume à la tente, gardée par un seul soldat, où le nouveau monarque reçoit Pardaillan, devant une table couverte de cartes et au son des coups de canon (ibid.).

Le spectacle de la violence, de la souffrance ou de la mort dans toute sa brutalité et sa crudité, la débauche associée dans l'imaginaire collectif à la cour des Valois sont hors champ. La plus grande frustration concerne le massacre de la Saint-Barthélemy, pour lequel on se contente d'une scène où Guise, au son du glas (alors que c'était le tocsin...), traverse une rue éclairée de quelques brasiers et où gisent des mannequins faisant office de cadavres, ou d'une autre scène où les Pardaillan croisent des gens qui s'enfuient en criant (épisode 7).

Ce média ne peut être affiché ici. Veuillez vous reporter à l'édition en ligne http:// journals.openedition.org/tvseries/1921

On peut être tenté de voir du «Grand-Guignol» dans cette tentative maladroite de recréation d'un monde enfui ${ }^{56}$, mais pour être tout à fait juste dans l'analyse du contenu 
historique de la série, il importe de rappeler certains paramètres objectifs qui l'informent ${ }^{57}$. Premièrement, c'est une œuvre de télévision, qui ne peut pas se permettre de montrer les mêmes choses que le cinéma, a fortiori quand il prétend faire du film historique ${ }^{58}$. Il faut tenir compte du public visé et des modalités de diffusion de ce programme familial et dominical sur une chaîne publique, soumise à des impératifs de respect de la dignité humaine et de protection des mineurs, dans le cadre de la Haute autorité de communication audiovisuelle qui a précédé le Conseil Supérieur de l'Audiovisuel, instauré en 1989.

Par ailleurs, la télévision, en particulier ce type de programme de moyenne gamme, ne bénéficie pas des mêmes moyens techniques et financiers que le cinéma. Pour Le Chevalier de Pardaillan, on l'a dit, on travaille à l'économie, en tournant essentiellement en studio, sur le plateau 11 des Buttes-Chaumont, avec un nombre ridicule de figurants, quelques chevaux, un chien et en utilisant les décors et les costumes des collections de la SFP, pas tout neufs, mais de bonne qualité tout de même ${ }^{59}$. En outre, on tourne vite (12 à 13 minutes quotidiennes), sans laisser le temps aux comédiens de roder leur jeu, de s'imprégner de leurs personnages jusque dans les moindres nuances, comme on peut le faire dans le $7^{\mathrm{e}} \operatorname{art}^{60}$.

\section{Une dimension littéraire et théâtrale affirmée}

Le budget ne prévoit pas non plus l'emploi d'un conseiller historique, ce qui, de toute façon, n'aurait pas changé grand chose, vu qu'en 1986, au moment où le feuilleton est tourné, la recherche universitaire sur les guerres de Religion commence seulement à prendre son essor ${ }^{61}$. En témoigne la thèse de doctorat de Jacqueline Boucher, consacrée à Henri III et sa cour, soutenue en 1977. Toutefois son audience reste très faible, même dans le milieu académique ${ }^{62}$.

Surtout, il ne faut pas oublier que la matrice de la série est un roman d'aventures, pas un roman historique au sens de ceux de Zola ou Hugo ou même de Dumas, nettement plus didactiques et saturés de descriptions détaillées, nourries d'érudition ${ }^{63}$. Zévaco, lui, écrit vite, de manière quasi industrielle, en s'aidant de fiches sur les noms de lieux, de personnes, les dates, les coutumes ${ }^{64}$. Dans un roman de cape et d'épée, c'est l'aventure qui prime et qui dicte tout le reste. Les décors sont peu nombreux et leurs descriptions minimales : le but est uniquement d'instaurer une ambiance le plus souvent nocturne, oppressante voire morbide, que l'on retrouve dans la série. L'action se déploie dans des endroits étriqués, propices aux conspirations ou aux combats, tels que les boudoirs, les alcôves, les cabinets de travail, les couvents, les auberges, les prisons, les coins de rue, pour la plupart, à Paris et au Louvre, qui, chez Zévaco, comme chez Dumas, constituent le centre de gravité du récit ${ }^{65}$. Ainsi, dans le roman, Paris est décrit comme une rue :

La nuit, les maisons mal alignées, les toits pentus, les tourelles et les girouettes qui crèvent le ciel obscur, l'alignement des enseignes qui, pareilles à des hallebardes, se hérissent d'un bord à l'autre, les bornes cavalières espacées comme des fantômes en faction, les façades à croisillons aux vitraux desquels la lune dessine des contours gothiques, la chaussée défoncée par places, son ruisseau au milieu, encaissé de pavés disloqués, les flaques d'eau, le silence énorme et, sur tout cela cette ombre, l'ombre des églises innombrables et sur ce silence, les heures qui tombent de ces clochers comme autant de voix de bronze qui s'envoient des salutations ${ }^{66}$. 
lors, le minimalisme de la représentation de la capitale dans la série peut être interprété comme un souci de fidélité à l'œuvre originale. Les personnages sont eux aussi croqués en quelques mots, visant à en dresser un portrait moral ou psychologique et non à en fournir une image complète et précise. Par exemple, Catherine de Médicis est dépeinte comme "une femme grande, maigre, tout enveloppée de noir, avec une tête d'oiseau de proie, nez de vautour, bouche serrée, regard perçant ${ }^{67} »$. Henri de Guise est « un jeune homme de haute taille, bien pris, avec un visage où éclatait un somptueux orgueil, un grand manteau de satin bleu flottant sur ses épaules et sa toque portant un triple rang de perles ${ }^{68}$. » beaucoup au théâtre. Ainsi, la série se caractérise par la prédominance des dialogues et des monologues, entrecoupés de scènes d'action (course-poursuite, duel à l'épée ou bagarre), d'entrées et de sorties fracassantes et de rebondissements improbables ${ }^{69}$. Cet aspect théâtral de la série, qui peut-être perçu comme artificiel ou manquant de naturalisme, est accentué par l'influence des dramatiques vidéos des années 1950 dont elle est l'héritière et par la formation de sa réalisatrice Josée Dayan qui a fait ses premières armes en captant des pièces de théâtre.

Ainsi, tout comme le roman dont elle est tirée et au-delà des défauts formels inhérents à ses modalités de fabrication, la série Le Chevalier de Pardaillan doit être appréciée pour ce qu'elle est en premier lieu « un trompe-l'œil qui abolit la succession des générations ${ }^{70}$ » et dont la finalité n'est pas de montrer la réalité, mais l'idée que peuvent s'en faire l'auteur de cette fiction et le large public à qui elle se destine ${ }^{71}$. Car, comme le roman historique, la série historique est un genre hybride, ambigu, « une représentation aux deux sens du terme : tout à la fois une image vraisemblable de la réalité et un miroir de l'imaginaire, de la culture d'une époque donnée ${ }^{72}$. »

\section{Le véhicule d'une mythologie nationale}

\section{Une période mal connue}

Dans Le Chevalier de Pardaillan, les guerres de Religion ne sont donc pas abordées dans leur intégralité. Au contraire, le contenu historique de la série témoigne à la fois d'une sélection drastique et d'un gauchissement des faits et des protagonistes. La série se divise en deux parties qui correspondent à deux séquences temporelles bien distinctes. La première partie, qui couvre les épisodes 1 à 7 et une partie du 8, est construite autour de la Saint-Barthélemy, tandis que la seconde (épisodes 8 à 15) est consacrée aux événements de Blois, autrement dit à l'affrontement entre le duc de Guise, chef de la Ligue catholique, et Henri III. L'un et l'autre n'ayant rien trouvé de mieux pour l'emporter sur son ennemi que de commanditer son meurtre, les deux hommes disparaissent à quelques mois d'intervalle, ce qui permet à Béarn de monter sur le trône. Le conflit civil, long et complexe, se résume donc à deux séquences violentes et tragiques et même à « un événement-choc », la Saint-Barthélemy, le seul que les Français ont tendance à retenir de cette période. Le régicide, quant à lui, est rejeté dans l'ombre, peut-être parce qu'il reste considéré par beaucoup comme le juste châtiment d'un monarque compromis dans le massacre et lui-même assassin ${ }^{73}$.

TV/Series, 10 | 2016 

marquées par de sinistres premières, on ne perçoit pas vraiment dans la série la logique, les enjeux et l'issue de ces événements extraordinaires : à savoir la préservation de la royauté - ou plutôt d'un certain système de gouvernement à tendance absolutiste - face à une alternative possible portée par les Grands (en partie soutenus par une opinion publique embryonnaire), ainsi que la pacification du royaume en réponse à un conflit confessionnel qui s'est rapidement politisé et militarisé, au point d'ébranler gravement la stabilité du pays et de l'État depuis 1562.

51 Cette interprétation des faits est le fruit de travaux d'histoire politique et sociale qui ont profondément changé notre compréhension des guerres de Religion, mais cette réflexion commençait seulement à s'engager au moment où la série a été écrite et réalisée. Ce n'est qu'à partir des années 1990, à la faveur de la commémoration du quatrième centenaire de l'Édit de Nantes, que le grand public s'est réapproprié cette page de son histoire, notamment par le biais de la télévision ${ }^{75}$. Par contraste, les commémorations en 1972 et en 1985 de ces «événements fondateurs négatifs » que sont le massacre de la SaintBarthélemy et la Révocation de l'Édit de Nantes n'avaient pas aussi fortement mobilisé les historiens et encore moins la télévision ${ }^{76}$. Ainsi, en 1985, la question de la Révocation n'est abordée à la télévision que par un numéro d'Apostrophes de Bernard Pivot, le 20 septembre, et par la diffusion le 9 octobre, toujours sur Antenne 2, d'un film de fiction tiré de faits réels, Les Prisonnières, de Stellio et Jean-Louis Lorenzi. saupoudrèrent leurs programmes d'un peu de bel-blanc-rouge avec plus ou moins de bonheur $^{78}$ " pour le Bicentenaire de la Révolution française, dans les années 1980, la télévision, même publique, confirme un renoncement à sa prétention passée d'être porteuse d'une « historiographie populaire », susceptible de toucher un public plus large que celui de l'école et de l'université ${ }^{79}$.

\section{Une collection d'images d'Epinal}

53 Cela dit, l'absence de dimension proprement historienne de ce programme n'explique pas, à elle seule, les ellipses et les distorsions dont l'histoire des guerres de Religion fait l'objet. Là encore, c'est le "caractère transgénérique et transmédiatique du récit populaire» porté par cette fiction télévisée qui est en cause et qui explique la prépondérance qu'on y observe de "topoï et d'images-icônes », caractéristiques d'une culture de masse, dont le roman est lui-même déjà le vecteur ${ }^{80}$.

Dans la série, l'évocation des événements et des personnages n'est qu'une succession de caricatures. Le massacre de la Saint-Barthélémy aurait ainsi été prémédité par la reine mère, qui aurait attiré à Paris les protestants sur le prétexte des noces de Béarn et de Margot et la signature d'un traité de paix, afin de «purger d'un seul coup le royaume de ces chiens d'hérétiques » (épisode 4). Catherine de Médicis aurait également empoisonné la reine de Navarre Jeanne d'Albret (épisode 4), et serait impliquée dans l'attentat de Maurevert contre Coligny. Sont également mis en scène un grand nombre d'images d'Epinal : rien que dans l'épisode 7, le miracle du bénitier de Saint-Germain l'Auxerrois, dont l'eau serait devenue du sang, en signe de la volonté divine; le fameux «tuez les tous ", parole apocryphe de Charles IX lorsque sa mère lui arrache l'ordre d'exécuter les huguenots; le coup de pied de Guise au cadavre de Coligny et la décapitation de ce dernier en vue de porter sa tête à Rome ; le roi chasseur voulant tirer à l'arquebuse depuis

TV/Series, 10 | 2016 
une fenêtre du Louvre sur les protestants en fuite; la Seine teintée du sang des victimes qu'on y a jetées ; l'agonie de Charles IX, hanté par les spectres de ceux qui sont morts sur son ordre et exsudant le sang, en rachat de celui qu'il a fait couler.

Dans la deuxième partie de la série, on a également droit à la stigmatisation de la Ligue, parti d'opposition catholique au roi, comme « ce damné conseil des Seize », ce « ramassis de nobliaux intrigants et de bourgeois grotesques» (épisode 8) ou de "brigands" (épisode 9), mais aussi au projet d'assassinat du roi par Guise lui-même, ou encore à cette autre phrase apocryphe : «il est plus grand mort que vif », lorsqu'Henri III aurait foulé du pied le visage de son rival défunt en signe de triomphe (épisode 14). L'assassinat du dernier des Valois est présenté comme un tyrannicide lorsque Jacques Clément le poignarde au cri de «Meurs, Hérode!», surnom que la Ligue a donné au roi. Enfin, le célébrissime "Paris vaut bien une messe » d'Henri IV devient une boutade soufflée par Pardaillan lui-même (épisode 15).

56 Les personnages historiques sont eux-mêmes montrés sous un jour complètement fantasmatique. Parmi eux, c'est incontestablement Catherine de Médicis qui tient la vedette. C'est elle la vraie méchante, «le mal personnifié », une veuve noire, faussement bigote, adepte de la magie et des prédictions astrologiques (épisode 4), mère indigne avec Charles, abusive avec Henri, prête à tout pour assouvir son inextinguible soif de pouvoir, emprisonnant ses propres fils et ses autres victimes dans la toile de ses mensonges doucereux, éliminant ceux qui la gênent par le poison ou par la lame des mercenaires à sa solde $^{81}$.

Ce média ne peut être affiché ici. Veuillez vous reporter à l'édition en ligne http:// journals.openedition.org/tvseries/1921

À côté d'elle, ses rejetons dégénérés font pâle figure. L'aîné est une créature pathétique, physiquement chétif, psychiquement instable (épisode 7), atteint de crises d'épilepsie qui le laissent toujours plus diminué, un homme-enfant aisément manipulable, obsédé par la chasse et mortellement jaloux de son frère. Il est racheté par son amour sincère pour sa maîtresse Marie Touchet et leur fils Charles, ainsi que par sa mort précoce et expiatoire d'un crime auquel il a consenti sans le souhaiter. Henri, le cadet, apparaît tout aussi névrosé que son aîné, adulé d'une génitrice dont il aspire à s'émanciper, taxé d'inceste avec sa sœur Marguerite, efféminé et même travesti (figure X). Quoiqu'Henri ne soit pas dénué d'intelligence, celle-ci est cependant invalidée par sa lâcheté, qui le pousse à céder aux criminels arguments de sa mère qui lui martèle que "pour vivre, il faut tuer " (épisode 14).

Autour de «cette tribu œdipienne» digne des Atrides gravitent des personnages secondaires moins étoffés quoiqu'entourés de la même aura négative ou positive ${ }^{82}$. Il y a, par ordre d'importance, le duc de Guise, un homme de guerre pas très subtil, adulé du peuple de Paris parce qu'il se pose en champion de la foi catholique, qui se dit descendant de Charlemagne et qui brigue par conséquent la couronne de France, quitte à occire son détenteur. Viennent ensuite le maréchal de Montmorency-Damville, un aristocrate fourbe et hautain, préoccupé de ses seuls intérêts et la duchesse de Montpensier, sœur du duc de Guise, une virago aux mœurs légères, qui ne songe qu'à supprimer Henri de Valois. Face à eux, se dressent François de Montmorency, frère aîné du maréchal, un baron loyal à la Couronne et catholique modéré, favorable à la tolérance civile envers les protestants ; Jeanne d'Albret, reine de Navarre, à la tête du parti huguenot, pétrie d'ambitions pour son 
fils ; Navarre ou Béarn, un jeune écervelé au fort accent méridional et prolixe en jurons, coureur de jupons bien que promis à "la grosse Margot", prêt à aller à la messe par opportunisme ou pour sauver sa vie, un peu plus mûr lorsqu'il devient roi dans le dernier épisode. Coligny apparaît comme un austère vieillard que Charles IX appelle «mon père ", chef de guerre des huguenots, s'ingéniant à convaincre le roi d'aller combattre aux Pays-Bas les troupes du roi d'Espagne pour secourir ses coreligionnaires, et qui meurt dans la plus grande dignité lors de la Saint-Barthélemy.

En fait, la série campe un tout petit nombre de personnages historiques réels. Hormis les plus puissants, la plupart ne jouent que les utilités. Rien de surprenant à cela : c'est le propre de ces romans historiques du XIXe siècle et du début XXe consacrés aux guerres de Religion que de condenser l'action autour d'événements paroxystiques et d'en restreindre les protagonistes. Comme le montre Philippe Joutard, les personnages sont distribués en deux groupes, « les bons, les blancs, plutôt protestants, et les méchants, les noirs, responsables des crimes et plutôt catholiques ${ }^{83}$ ». Cependant, les romanciers populaires se révèlent "médiocrement intéressés par leurs tempéraments ou leurs destins", notamment en ce qui concerne «les grandes figures protestantes qui les inspirent fort peu ", ainsi que les Guise, "dont les silhouettes sont dessinées sans grand enthousiasme, comme l'antithèse des huguenots, presque toujours sombres et cruels ${ }^{84}$. "

Si les personnages historiques manquent à ce point d'épaisseur, dans la série comme dans le roman dont elle est tirée, c'est parce que leurs auteurs font le choix de puiser dans une " collection d'images d'Épinal, fausses pour la plupart », en ignorant volontairement le profit qu'ils pourrait tirer de la littérature scientifique en vue de donner de ces personnages une image plus nuancée, à défaut de véridique.

63 Ainsi, dans Le Chevalier de Pardaillan, on ne retrouve nul écho des biographies se revendiquant comme sérieuses qu'ont livrées de Catherine de Médicis et d'Henri III Jean Orieux et Pierre Chevallier chez Flammarion en 1986 et chez Fayard en 1985. Encore récemment, dans son roman à succès, Charly 9, publié en 2011 chez Julliard, pour faire revivre "ce monarque calamiteux mais qui avait un bon fond", Jean Teulé accorde bien plus de crédit aux écrits de Brantôme, d'Agrippa d'Aubigné, de Pierre de l'Étoile, mais aussi de Mérimée, de Chénier ou de Michelet qu'à ceux de ses biographes ou des historiens spécialistes de l'époque. À l'inverse, dans la bande dessinée consacrée en 2015 à Catherine de Médicis dans la collection «Ils ont fait l'histoire », les auteurs intègrent le contenu des ouvrages de référence publiés dix ans plus tôt par Thierry Wanegffelen et Denis Crouzet ${ }^{85}$.

\section{Des sources historiques authentiques mais orientées}

64 La plupart du temps, afin d'accroître son impact émotionnel et de faciliter la réception de l'œuvre par un large public, les auteurs de fictions historiques, littéraires et/ou télévisuelles, préfèrent jouer sur des images mentales toutes faites et familières, qu'ils ne créent pas, mais qu'ils revisitent, revitalisent sans cesse, à partir des mêmes «sources d'époque ${ }^{86}$. " Le scénariste de la série et, avant lui, Zévaco n'inventent rien: ils ne font que reproduire, de manière totalement assumée, la matrice élaborée par Dumas et ses contemporains, romanciers, artistes, historiens (Taine, Guizot, Michelet), dont l'imagination romantique a exploité l'abondante manne de sources historiques qu'ils avaient à leur disposition. 
65 à travers la publication d'une documentation historique inédite et extrêmement riche. Le
hic, c'est qu'il s'agit de sources narratives ou polémiques : des lettres, des mémoires et des
chroniques (Brantôme, d'Aubigné, Montluc, Pasquier, L'Estoile, de Thou), des pamphlets
et des libelles, dont les auteurs, illustres ou anonymes, avaient à cœur soit de se donner le
beau rôle ou de se disculper devant le tribunal de la postérité, soit de se faire les chantres
d'une version officielle des faits, soit, au contraire, de défendre avec vigueur le point de
vue de l'un ou l'autre camp, politique et/ou religieux ${ }^{87}$. Pourtant, c'est au premier degré,
sans y appliquer les règles de la critique auxquelles s'astreint l'historien de métier que ces
sources sont lues et reprises par Dumas et ses émules, " qui y ont puisé ce qu'elles
contenaient de plus spectaculaire et de dramatique, sans remettre en question leur
objectivité et qui ont projeté cet amalgame sur le public, en y ajoutant les enflures et les
fioritures propres à la sensibilité de leur époque ${ }^{88}$.»
Rien d'étonnant dès lors, si, dans l'épisode 14 du Chevalier de Pardaillan, la scène de
l'assassinat du duc de Guise offre de troublantes similitudes avec le tableau de Paul
Delaroche, L'assassinat du duc de Guise, très admiré au salon de 1835 et visible aujourd'hui
au château de Blois.

Figure 9 : Paul Delaroche, L'assassinat du duc de Guise, Chantilly, Musée de Condé, 1834

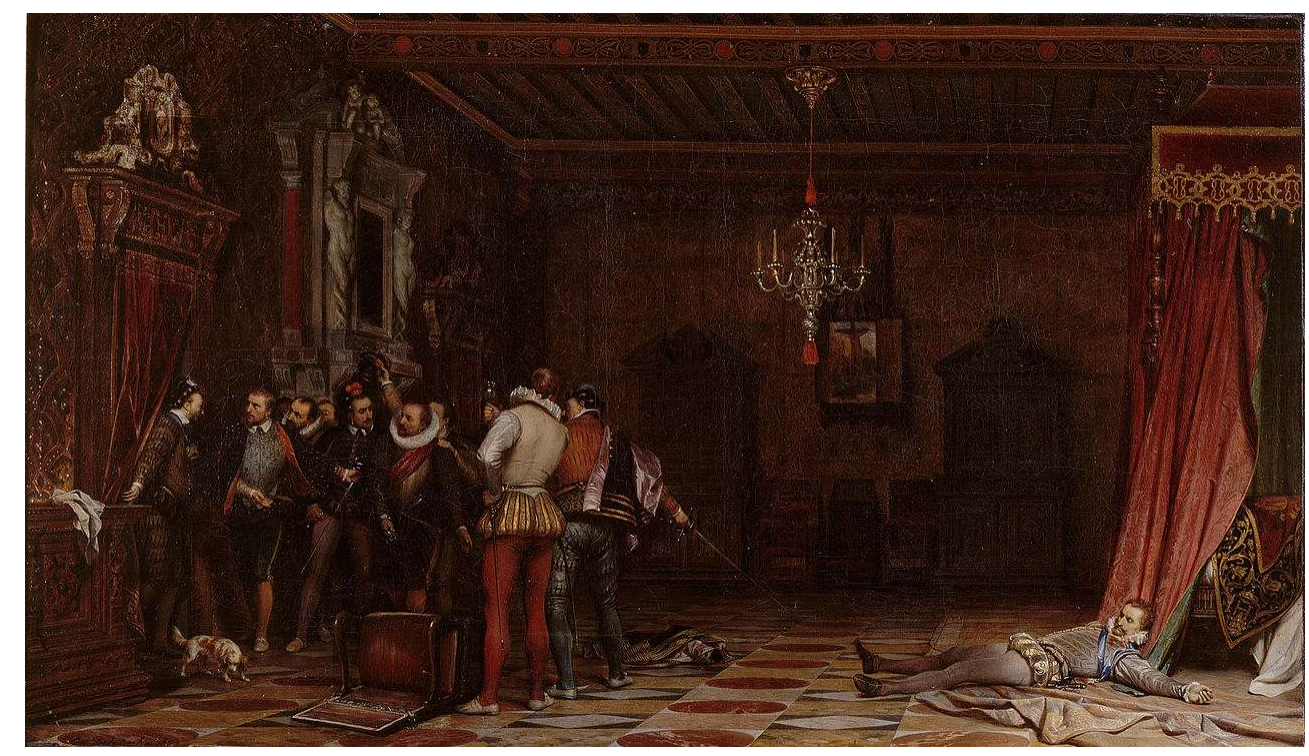


Figure 10 : L'assassinat du duc de Guise dans Le Chevalier de Pardaillan (épisode 14)

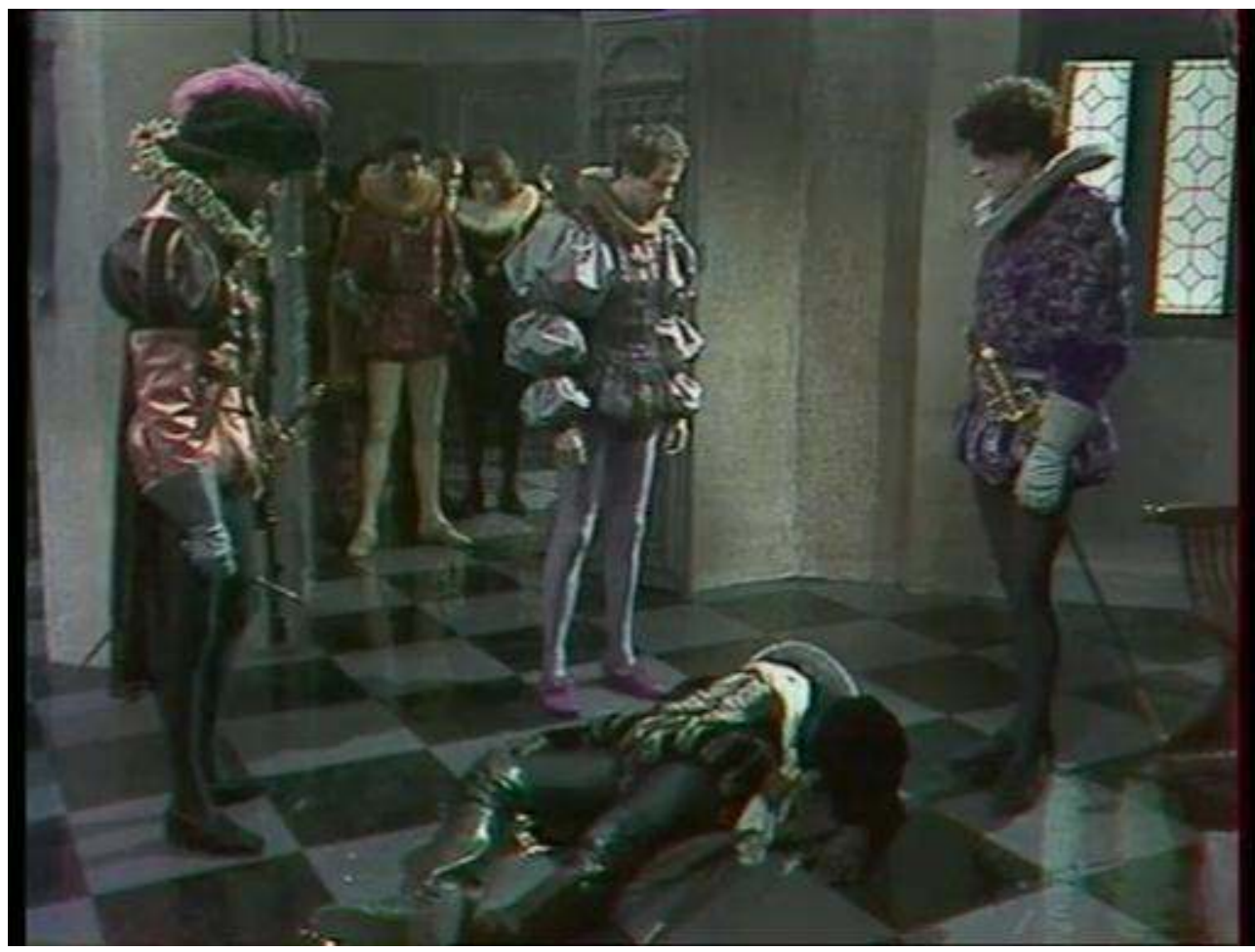

Figure 11 : Charles Barthélemy Durupt, Henri III poussant du pied le cadavre du duc de Guise, Château de Blois, peint en 1832

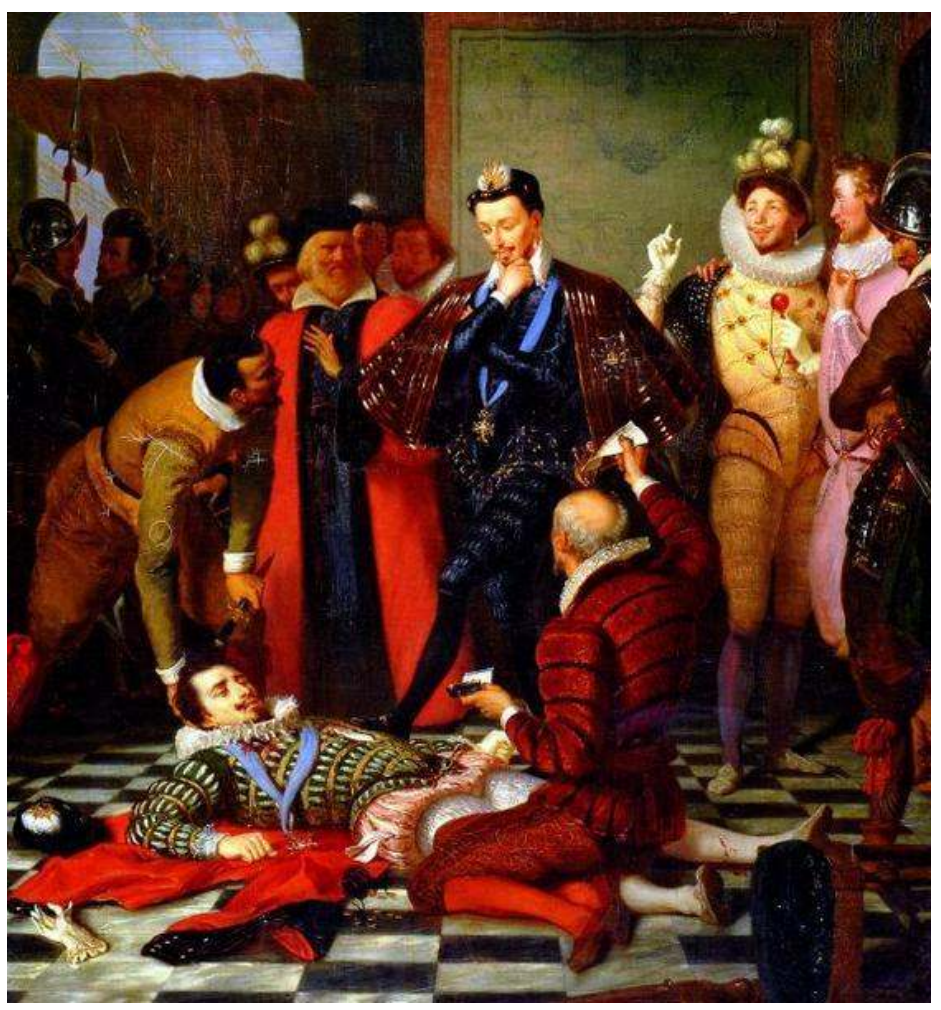

Un détail du tableau de Charles Barthélemy Durupt, Henri III poussant du pied le cadavre du duc de Guise, peint en 1832, est également transposé presque tel quel à l'écran. 
Figure 12 : Gros plan lors de l'assassinat du duc de Guise dans Le Chevalier de Pardaillan (épisode 14)

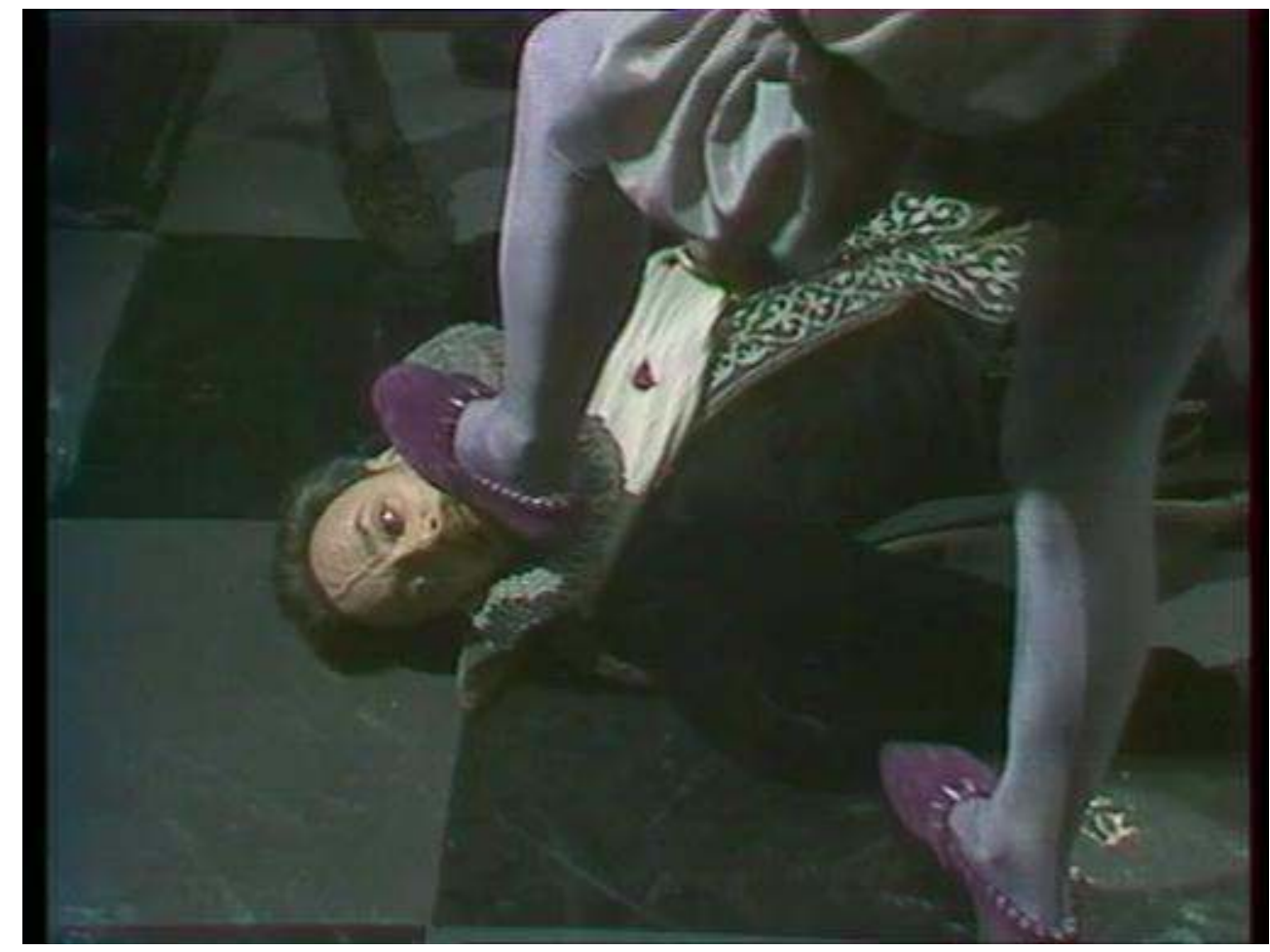

On assiste à la même chose pour la scène de l'assassinat d'Henri III, à l'épisode 15 , très semblable au tableau de Hugues Merle, exposé au Salon de 1863 et également conservé à Blois. 
Figure 13 : Hugues Merle, L'Assassinat d'Henri III, Château de Blois, 1863

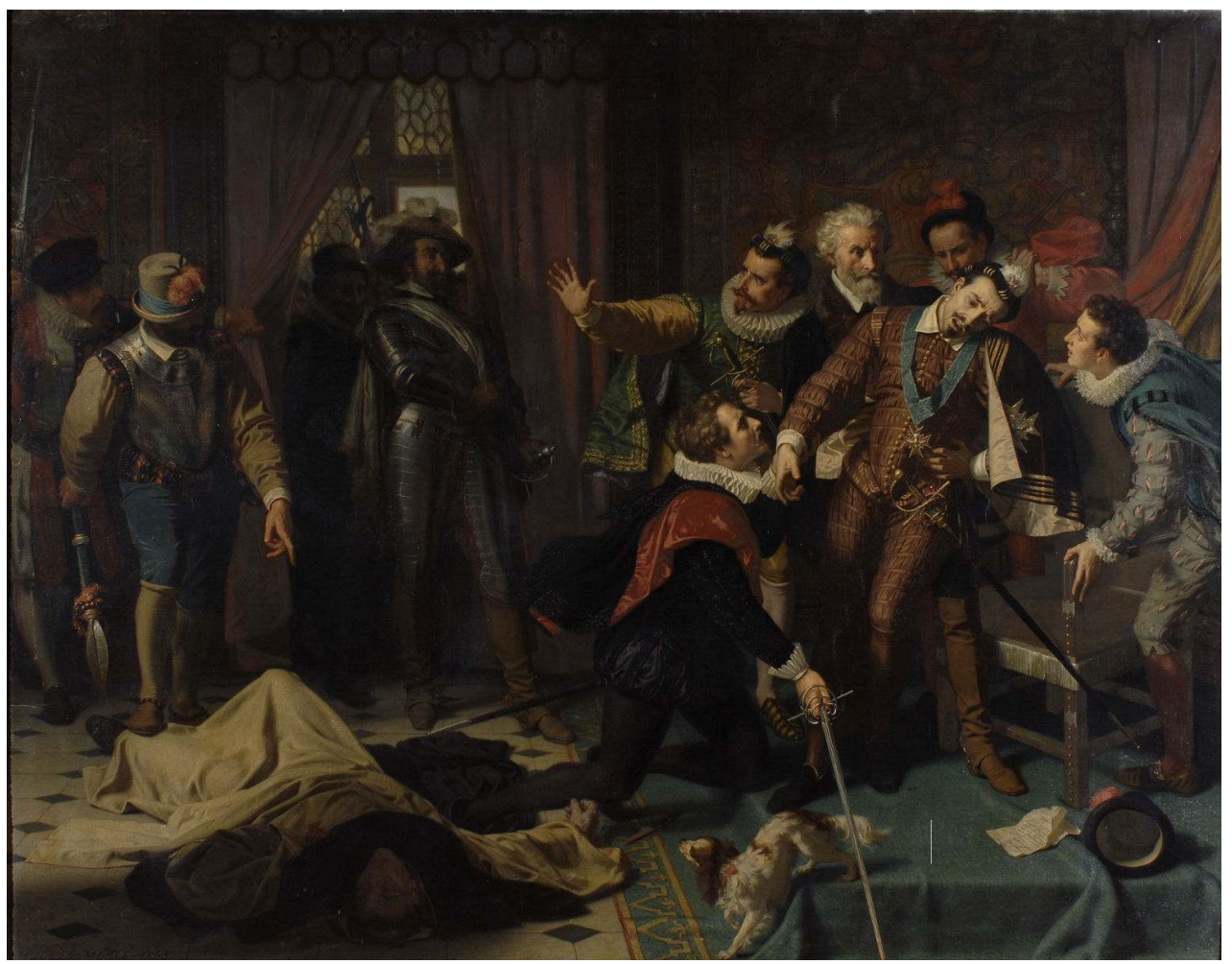

Figure 14 : L'assassinat d'Henri III dans Le Chevalier de Pardaillan (épisode 15)

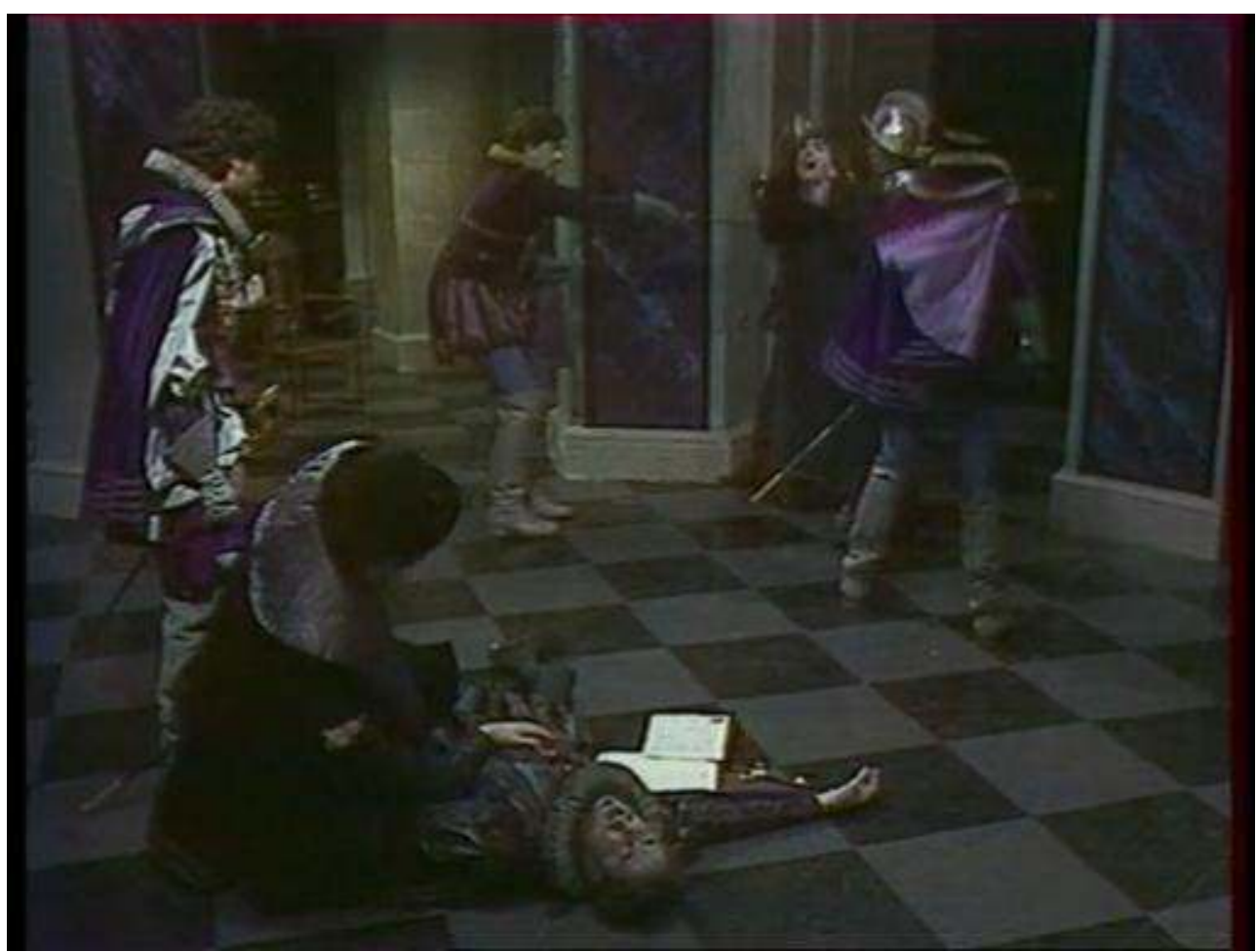

En outre, c'est dans les registres-journaux de Pierre de l'Estoile, l'auteur du XVI ${ }^{e}$ siècle sur lequel Dumas s'appuie le plus, que l'on trouve le récit de la mort du duc de Guise, 
repris presque mot à mot dans la série : « le vingt-troisiesme decembre est la mort du duc de Guise... et fut là son corps jeté sur un tapis et là laissé quelque temps exposé aux mocqueries des courtisans qui l'appelloient le beau roy de Paris, nom que luy avoit donné le roi » qui, une fois le duc mort, sortit de son cabinet et «donna un coup de pied au visage de ce pauvre mort, ainsi que le duc de Guise avoit donné au feu admiral de Chastillon et le roy, l'ayant un peu contemplé, dit Mon Dieu, qu'il est grand! Il paroist un corps plus grand mort que vif ${ }^{89}$.»

La confession de Catherine de Médicis sur son lit de mort à l'épisode 15 et le réquisitoire du duc de Guise à l'encontre d'Henri III à l'épisode 10 retranscrivent, presque mot à mot, les pamphlets diffamatoires émanant des protestants pour l'une, des ligueurs pour l'autre. Et ce ne sont là que quelques exemples parmi d'autres de l'intertextualité et des effets de décalque visuels que l'on détecte entre la série et les œuvres littéraires et/ou iconographiques dont elle est tributaire.

69 Néanmoins, les jeux de miroir ne s'arrêtent pas là dans Le Chevalier de Pardaillan. On constate que Zévaco n'est pas un servile imitateur de Dumas, dont il se démarque nettement puisque, dans la série, sont absents Marguerite de Valois et François-Hercule d'Alençon-Anjou, le plus jeune fils de Catherine de Médicis et d'Henri II. En outre, Navarre/Béarn n'y apparaît que très peu et pas de manière flatteuse de surcroît, alors que Dumas, lui, fait de ces trois personnages les protagonistes principaux de ses romans et, comme beaucoup de ses contemporains, rend un véritable culte au premier Bourbon ${ }^{90}$.

Cette différence majeure entre les œuvres de Dumas et Zévaco est peut-être due au fait que le second écrit un demi siècle après le premier, dans un contexte culturel qui n'est plus le même et qui infléchit sans doute sa vision de l'histoire. Car, « même si ces romans se posent comme apolitiques, écrits dans le seul but de distraire et d'instruire, ils sont en fait porteurs d'une lecture de l'histoire qui s'inscrit dans un camp et qui s'impose d'autant mieux à travers la fiction que le parti-pris idéologique n'est nulle part affichép ${ }^{1}$. »

\section{Un jeu de miroirs}

\section{Une vision patriote et républicaine de l'Histoire}

71 À un moment de l'épisode 2, Pardaillan déclare : «nous vivons des temps intéressants, mais troublés». Cette petite phrase est extrêmement révélatrice de la démarche idéologique adoptée par Zévaco et dont il n'a pas le monopole parmi les auteurs de romans historiques populaires. Car ceux-ci ne s'intéressent pas aux guerres de Religion par hasard. Le choix d'une période historique où situer son intrigue est littéralement identitaire pour ces romanciers " parce qu'il témoigne du rapport qu'une société donnée entretient avec son passé : la comparaison ou plutôt la confrontation qui en résulte met à nu les traits distinctifs d'une image de soi ${ }^{92}$. " Dès lors, si ceux-ci s'emparent avec une belle unanimité de cette époque, ce n'est pas uniquement parce qu'elle est particulièrement mouvementée et excitante, "perversement attirante par ses excès ", offrant un cadre idéal pour l'aventure et l'expression d'une esthétique répudiant la tempérance du classicisme, "comme si l'ordre et l'unité nationale étaient des terrains stériles pour la fiction ${ }^{93} . »$

72 L'autre raison de ce tropisme pour les guerres de Religion et la première modernitée ${ }^{94}$ en général, perçues comme pionnières dans la construction étatique, l'affirmation du 
sentiment national et l'éveil politique du peuple, réside dans le besoin qu'éprouvent ces romanciers d'interroger le passé pour mieux penser l'impensable de 1789, puis la lente et incomplète installation de la démocratie au XIX ${ }^{e}$ siècle, surtout dans le cas d'auteurs aux idées radicales comme Zévaco ${ }^{95}$.

C'est pourquoi ces fictions historiques sont porteuses, en filigrane, d'un substrat idéologique qui se laisse assez facilement apercevoir dans le cas du Chevalier de Pardaillan. Dans la série, la guerre civile est montrée voire dénoncée comme le résultat d'une compétition féodale, donc rétrograde, entre des clans dynastiques rivaux prêts à s'entretuer pour accéder au pouvoir suprême ou le conserver, et qui dissimulent leur triviales motivations sous le manteau de la défense de la religion (épisode 4) ${ }^{96}$.

Cette vision des choses n'est pas l'apanage de Zévaco : c'est aussi celle des romanciers du $\mathrm{XIX}^{\mathrm{e}}$ siècle, échaudés par les dérives impériales de leur temps et nourris d'une sorte de vulgate des guerres de Religion. Dès la fin du XVI ${ }^{e}$ siècle, des juristes dits Politiques considéraient que l'intérêt de l'État devait passer avant celui de la religion et voyaient en Henri IV un homme providentiel, « un roi de raison », capable de restaurer à l'intérieur l'unité du royaume par la mise en œuvre d'une tolérance religieuse et de le protéger de l'extérieur par l'instauration d'un régime fort et la lutte ouverte contre les puissances étrangères. Cette version officielle des faits a été par la suite développée par les thuriféraires du premier Bourbon et les chantres de la monarchie absolue, mais aussi par Voltaire dans sa Henriade et par les historiens du XIX ${ }^{\mathrm{e}}$ siècle et du début XX $\mathrm{XX}^{\mathrm{e}}$ tels LouisPierre Anquetil (dont Dumas avait fait son livre de chevet), Jules Michelet et Ernest Lavisse $^{97}$.

C'est ce qui explique également - outre la vogue du roman patriote qui sévit au début du $\mathrm{XX}^{\mathrm{e}}$ siècle dans un contexte de réveil des nationalismes - que, dans la série, tout comme chez Zévaco, les personnages les plus nuisibles sont des étrangers aux visées hégémoniques : Catherine la Florentine, Fausta l'Italienne, Guise le Lorrain (donc quasi germanique) et Philippe II l'Espagnol. À l'inverse, les héros positifs sont des Méridionaux, truculents, spirituels et braves, incarnant en quelque sorte "la France éternelle»: Pardaillan, mais aussi Béarn, semblables aux figures familières de d'Artagnan, du baron de Sigognac dans Le Capitaine Fracasse, ou encore de Pierre de Siorac dans Fortune de France de Robert Merle ${ }^{98}$.

76 Cette lecture politique de l'histoire n'est pas dénuée non plus d'une dimension morale et même philosophique. Ainsi qu'on peut le constater dans les discours de Catherine de Médicis, faisant l'apologie des pires méfaits au nom du principe que la fin justifie les moyens, Zévaco, (comme Dumas) reprend à son compte l'anti-machiavélisme des détracteurs contemporains des Valois. La politique est dépeinte comme le fruit de funestes passions, d'une volonté de possession des biens comme des personnes, sans aucune préoccupation pour l'intérêt commun. On distingue ici nettement l'écho des écrits de Rousseau ${ }^{99}$, de La Comédie humaine de Balzac ${ }^{100}$ ou encore d'Humain trop humain de Friedrich Nietzsche ${ }^{101}$.

77 Quand, dans les années 1960-70, Jean-Paul Sartre ou Jean-Louis Bory rendent hommage à Zévaco, c'est comme «cet auteur de génie qui, sous l'influence de Hugo, a inventé le roman de cape et d'épée républicain ${ }^{102}$ " et dont la leçon fleure bon l'humanisme républicain, laïc et démocratique ${ }^{103}$ ». Car «Pardaillan, c'est le peuple, le biceps et la gouaille. Un Lagardère qui aurait lu Michelet. C'est d'Artagnan mousquetaire du rocambolesque radical-socialiste (quand radical-socialiste signifiait quelque chose) ${ }^{104}$ ». 


\section{Une apologie à peine voilée de la révolte et du féminisme} français, le dernier des romantiques ${ }^{107}$ ", Michel Zévaco était fasciné par la Commune. Proche de Louise Michel, il fut un socialiste révolutionnaire à tendance marxiste, voire libertaire. Collaborateur d'Aristide Briand et de Jean Jaurès, il s'insurgeait contre ce qu'il appelle "le Gésu », c'est-à-dire le pouvoir catholique et clérical. Il était violemment opposé à toute forme d'oppression, que ce soit par la religion, la justice, la police ou l'argent. Féministe, il prônait l'union libre, l'égalité homme-femme et le droit à l'avortement. Ses tribunes virulentes dans la presse de gauche l'envoyèrent deux fois en prison au tournant des années 1880-90108. stigmatisée comme une forme de tyrannie, où l'arbitraire d'un seul, même inapte, n'est contrebalancé par aucun contrepoids institutionnel. La seule issue est alors le soulèvement populaire, à la fois redouté et méprisé des princes, qui le perçoivent uniquement comme une pulsion colérique et puérile de gens dont il faut flatter les bas instincts si on veut en rester maître. Les puissants abusent ainsi de la crédulité du peuple en ayant recours à des prédictions apocalyptiques, et de façon générale à la religion, à laquelle même les membres du clergé ne croient pas vraiment.

En outre, dans Le Chevalier de Pardaillan, ce sont les femmes qui tiennent le haut du pavé : monstres ou martyres, princesses, tenancières ou filles de joie, femmes de tête ou de cœur, animées par le désir de domination, l'amour ou la revanche, elles se jouent des 
hommes, les défient et les battent sur leur propre terrain, quitte à y laisser la vie, accédant par là même au rang d'héroïnes à part entière. C'est une particularité de la série qui contraste avec les romans de Dumas, qui reflètent davantage d'anciens et tenaces préjugés misogynes sur « la nocivité des femmes au ou de pouvoir » et dont Catherine de Médicis est dès lors la parfaite illustration ${ }^{109}$. Cet aspect singularise l'œuvre de Zévaco, étant donné que, traditionnellement, dans le roman populaire :

La femme n'occupe qu'une position secondaire ou ne remplit qu'un rôle négatif, ne sortant de cette subordination narrative qu'avec la vogue du roman de la victime dans le dernier tiers du XIX siècle et encore, sa centralité se manifeste alors de manière très différente de celle de sa contre partie masculine: au fantasme de pouvoir illimité de l'homme s'oppose la passivité totale de la femme ${ }^{110}$.

Ainsi, dans Le Chevalier de Pardaillan, les femmes ne deviennent dangereuses que lorsqu'elles décident de secouer le joug sous lequel les hommes les maintiennent et d'accomplir leur destin, qui ne se résume pas au mariage et à la maternité.

Il ressort de cette analyse qu'en mettant discrètement en garde le public contre les éventuelles dérives liberticides du pouvoir étatique et contre le fanatisme religieux, en flattant la fibre patriotique des Français, en prônant l'égalité, la tolérance et la fraternité, la série télévisée ne trahit en rien l'esprit du roman de Zévaco, sûrement parce que ses auteurs partageaient, en grande partie, les vues de l'écrivain et s'attendaient à ce que ce fût aussi le cas des téléspectateurs.

Bien qu'il s'agisse d'une œuvre de commande, assez formatée dans le fond comme dans la forme, on peut supposer que la réalisatrice, en accord avec le scénariste, a respecté et conservé le message sous-jacent dans le roman, parce qu'il était conforme à ses valeurs à elle et à celles de la plupart de ses compatriotes de la fin des années 1980. Fille d'un juif algérien, ayant connu les affres de la décolonisation et l'enthousiasme de mai 68 , gavée de films de séries B et de westerns dans son enfance, admiratrice de Balzac, de Simone de Beauvoir, de Marguerite Duras et de Catherine de Médicis, homosexuelle déclarée quoique pas militante, Josée Dayan avoue, dans ses interviews, que ses productions sont «très ancrées dans la vision qu'elle a de la société actuelle, plus dure, plus angoissée, moins permissive et moins frivole qu'au début des années $1970^{111}$. Elle revendique « une relecture des classiques en prise avec le monde d'aujourd'hui ${ }^{112}$ » et une réflexion sur «le pouvoir qui corrompt et qui détruit ${ }^{113} »$.

Ces propos ont certes été tenus au début des années 2000, au moment où ses adaptations du Comte de Monte Cristo et des Rois maudits ont achevé de faire de Josée Dayan, la «madone de l'Audimat ${ }^{114}$ ». Cependant, il n'est pas douteux que la débutante astreinte aux impératifs de la «spaderie » qu'elle était lors du tournage du Chevalier de Pardaillan concevait déjà son travail de cette manière et qu'elle l'a instillé, même de manière superficielle, dans cette production mineure.

87 L'influence des séries western américaines, «forme déguisée du drame réaliste, où les problèmes contemporains peuvent être traités sur un terrain idéalisé et dont les personnages se comprennent comme des archétypes, incarnant une facette de la nature humaine et passibles d'un jugement moral selon des critères universellement admis ${ }^{115}$ " est également perceptible. Car Le Chevalier de Pardaillan s'inscrit, on l'a dit, dans la lignée des feuilletons qualifiés de « westerns à la française »: 
dont les thèmes sont proches du genre cinématographique américain par excellence : le héros solitaire, le justicier, la vengeance, l'amitié virile, école à laquelle on a quelquefois reproché sa tendance idéologique plutôt située à gauche, ces œuvres traitant en sous-entendu un message politique, une réflexion sur l'opposition et la misère du peuple, le pouvoir et la justice, la liberté, la révolution et la république ${ }^{116}$.

\section{Un programme politiquement correct dans les années 1980} ne prétend fournir les clefs de la compréhension des mécanismes d'une époque qui échappera toujours à l'entendement, du fait de sources lacunaires et pas toujours fiables, et quels que soient les progrès de l'historiographie savante, qui se borne, après tout, à proposer elle aussi un récit du passé où, en principe, l'imagination n'aurait pas sa place ${ }^{123}$. Toutefois, "par un kaléidoscope d'images, de sons, de couleurs, de personnages et 
d'aventures ${ }^{124}$ ", la série permet au public "de sentir l'épaisseur et la complexité d'une certaine réalité historique» et, éventuellement, de l'inciter à aller plus loin dans son exploration et sa connaissance, voire de susciter des vocations d'historien amateur ou professionnel, soucieux de faire la part des choses entre des représentations romanesques et mythologiques et les enseignements de la science ${ }^{125}$.

Car, le fait que ce type d'œuvre soit prioritairement - quoique pas uniquement - voué à procurer une forme d'évasion à son public, voire une forme de compensation à ses frustrations par l'identification à des personnages hors du commun, n'implique pas qu'elle ne présente aucun intérêt du point de vue historique et, plus largement, culturel. Une analyse attentive aux spécificités voire aux ambiguïtés de cet artefact à la fois idéologique et commercial qu'elle constitue fait apparaitre que, tout comme le roman qui en est à l'origine, cette série télévisée peut être considérée comme le vecteur d'une mémoire collective, pas au sens historien du terme, c'est-à-dire objective, érudite, si possible véridique, mais au sens anthropologique, c'est-à-dire subjective, affective, parfois fantaisiste certes, et pourtant significative et rassembleuse ${ }^{126}$.

En dépit de ses défauts formels, inhérents au genre et au contexte spécifiques auxquels elle appartient, la série donne vie à des archétypes historiques et moraux qui peuplent avec constance l'univers mental des Français. Elle leur permet de se reconnaître comme un peuple uni par des errements et des accomplissements qu'ils ont reçus comme un héritage qu'il leur appartient de perpétuer ou de sublimer en fonction de la lecture qui leur est suggérée du passé et de ses liens avec le présent. La connivence entre le créateur de l'œuvre et son consommateur qui sait très bien, au fond, à quoi s'en tenir sur la teneur de cette opération à remonter le temps, ne doit pas être sous-estimée ${ }^{127}$.

\section{Ouvrages et articles généraux}

BENASSI Stéphane, Séries et feuilletons TV. Pour une typologie des fictions télévisuelles, Liège, Éditions du CEFAL, 2000.

BOUTET Marjolaine, Les Séries télé pour les nuls, Paris, Éditions First, 2009.

BOUTET Marjolaine, « Soixante ans d'histoire des séries télévisées américaines », Revue de recherche en civilisation américaine, $\mathrm{n}^{\circ}$ 2, 2010, https://rrca.revues.org/248 consulté le 26 avril 2016.

BOUTET Marjolaine, « Depuis quand les Français sont-ils accros aux séries TV ? », Inaglobal, 24 avril 2014 [mis à jour 17 avril 2015], http://www.inaglobal.fr/television/article/depuis-quand-lesfrancais-sont-ils-accros-aux-series-tv-7551, consulté le 16 avril 2016.

BuXTon David, De «Bonanza » à « Miami vice », formes et idéologies dans les séries télévisées, La Garenne-Colombes, L’Espace européen, 1991

BUXTON David, Les séries télévisées. Formes, idéologie et mode de production, Paris, L'Harmattan, 2010. 
CARRAZÉ Alain, Les séries télé. Toutes les clés, Paris, Hachette, 2007.

CHANIAC Régine, « La fiction en série : évolution de la programmation en France », Quaderni, n 9, hiver 1989-90, p. 11-17.

CUISSET François, La décennie. Le grand cauchemar des années 1980, Paris, La Découverte, 2006.

DUBS Delphine et Marie QUEVREUX, «La philosophie des séries télévisées : un territoire à (ré)explorer ", Implications philosophiques, http://www.implications-philosophiques.org/ semaines-thematiques/philosophie-des-series/la-philosophie-des-series-televisees-un-territoirea-reexplorer-introduction/ consulté le 16 avril 2016.

MAIGRET Éric et Guillaume soulez (éds.), «Les raisons d'aimer les séries télé », Mediamorphoses, hors série $\mathrm{n}^{\circ} 3$, janvier 2007, http://documents.irevues.inist.fr/handle/2042/23356 consulté le 16 avril 2016

\section{Le roman populaire}

AUDUREAU Annabel, « Étude des couvertures de la série des Fantômas dessinées par Gino Starace entre 1911 et 1913 », Belphégor. Littératures populaires et culture médiatique, 11/1, 2013, www.belphegor.revues.org/110 consulté le 16 avril 2016.

ARTIAGA Loïc (éd.), Le roman populaire. Des premiers feuilletons aux adaptations télévisées, Paris, Autrement, 2008.

AZIZA Claude, « Romanciers : le goût du sang », L'Histoire, Hors Série n 17, 2002, p. 86-87.

CAILloT Patrice, « Zévaco cinéaste », Les Cahiers de la Cinémathèque, n 28, 1979, p. 215-218

DEMARS Aline, Michel Zévaco et le roman feuilleton, thèse pour le doctorat d'Etat ès lettres, Paris-IVSorbonne, 1985.

DEMARS Aline, « Les romans modernes de Michel Zévaco », Romantisme, n 53, 1986, p. 107-122.

DEMARS Aline, «La Saint-Barthélemy dans Les Pardaillan », Cahiers de l'Imaginaire, numéro spécial Zévaco, 1987, n.p.

DEMARs Aline, « Préface à Michel Zévaco », Les Pardaillan, Paris, Robert Laffont, coll. « Bouquins », 1988.

FRIGERIO Vittorio, «Bons, belles et méchants (sans oublier les autres) : le roman populaire et ses héros ", éd. Loïc Artiaga, Le roman populaire. Des premiers feuilletons aux adaptations télévisées, Paris, Autrement, 2008., p. 100-110.

GARGUILO René, « Un genre majeur de la littérature populaire : le roman de cape et d'épée », Roman populaire et/ou roman historique, Monográfico de l'Ull Critic 4-5, 1999, p. 85-103.

GARRISSON Janine, « Préface », La Reine Margot, Alexandre Dumas, Paris, Gallimard, 2009.

KRULIC Brigitte, Fascination du roman historique : intrigues, images et femmes fatales, Paris, Autrement, 2007.

LETOURNEUX Matthieu, « Bibliothèque des grandes aventures. Michel Zévaco », http:// mletourneux.free.fr/ consulté le 16 avril 2016.

MOMBERT Sarah, «Les frères ennemis du roman historique. Sur quelques romans des XIXe et XXe siècles consacrés aux guerres de religion », Travaux de littérature, 1997, X, p. 281-293. 
ROUDIER Luce, Michel Zévaco : écrire l'Histoire, Mémoire de Master I Théorie de la Littérature, ENS/ EHESS, sous la direction de Judith Lyon-Caen, 2014.

ROUDIER Luce, La Fabrique Zévaco. Manufacture de l'écriture, Mémoire de Master II Théorie de la Littérature, ENS/EHESS, sous la direction de Judith Lyon-Caen, 2015.

ROUDIER Luce, « Michel Zévaco, entre histoire romancée et anarchie historique », in Ecrire l'histoire avec des «si », éd. Florian Besson et Jan Synowiecki, Paris, Editions de la rue d'Ulm, 2015, p. 39-47.

ROUDIER Luce, « Roman populaire et désengagement : la violence politique désactivée chez Michel Zévaco », Le Rocambole, n 73, 2015, p. 101-111.

VIENNOT Éliane, « De la Reine Marguerite à La Reine Margot : les lectures de l'histoire d'Alexandre Dumas », L'École des Lettres, n 13-14, 1994, www.elianeviennot.fr/Articles/Viennot-MgV-Dumashistoire.pdf, consulté le 16 avril 2016.

VIENNOT Éliane, « Le corps signifiant des souverains dans La Reine Margot d'Alexandre Dumas », éd. Jean-Marie Roulin, Corps, littérature, société, 1789-1900, Saint-Étienne, 2005, www.elianeviennot.fr/Articles/Viennot-MgV-Dumas-corps.pdf, consulté le 16 avril 2016.

\section{L'Histoire au cinéma et à la télévision}

AzızA Claude, Guide de l'Antiquité imaginaire, roman, cinéma, bande dessinée, Paris, Les Belles lettres, 2008.

BAUDOU Jacques et Jean-Jacques SCHLERET, Les feuilletons historiques de la télévision française de Thierry la Fronde à Maria Vandamme, Paris, Huitième Art Éditions, 1992.

BERTIE et la rédaction de lexpress.fr, « Pour une bonne série historique, reprenez la recette des Feux de l'amour ! ", L'Express.fr, http://www.lexpress.fr/culture/tele/pour-une-bonne-seriehistorique-reprenez-la-recette-des-feux-de-l-amour_1236203.html consulté le 16 avril 2016 BOUTET Marjolaine, «Les séries télévisées américaines des années 1980. Une autre histoire de la guerre du Vietnam ", Vingtième Siècle, n 84, hiver 2004, p. 61-73, https://www.cairn.info/revuevingtieme-siecle-revue-d-histoire-2004-4-page-61.htm consulté le 15 mai 2016.

CLARA, «Étude de cas : le pouvoir de séduction des séries historiques ", post de blog sur SériesChéries, 29 novembre 2013, https://seriescheries.com/2013/11/29/le-pouvoir-de-seductiondes-series-historiques/ consulté le 16 avril 2016.

DUMONT Hervé, Cinéma et histoire/Histoire et cinéma, Encyclopédie du film historique, volume 2 (Moyen Âge et Renaissance), chapitre 10 (La France déchirée par les guerres de Religion), www.hervedumont.ch, consulté le 16 avril 2016.

DE BAEQUE Antoine et Christian DELAGE (éds.), De l'histoire au cinéma, Bruxelles, Complexe, 1998. GOETSCHEL Pascale, "Compte-Rendu de Quand la télévision explore le temps... », Vingtième Siècle, vol. $72, \mathrm{n}^{\circ} 1,2001$, p. 163

JAUBERT Martine, Sylvie LALAGÜE-DULAC et Brigitte LOUICHON, « Les fictions historiques : un objet littéraire, éditorial et scolaire qui interroge les frontières ", Repères, $n^{\circ}$ 48, 2013, p. 7-16.

KECHROUD-GIBASSIER Christophe, « Entretien avec Josée Dayan », France 2, 2005, ww.cinemotions.com/interview/3438, consulté le 6 mai 2016. 
LE ROUX Nicolas, «Sexe, violence et histoire. Un XVI siècle de cinéma », conférence du 18 janvier 2012 au séminaire FRAMESPA, Lieux de construction du rapport au passé (medias, fiction, internet), www.blogs.univ-tlse2.fr, consulté le 16 avril 2016.

NORA Pierre et alii, « L'histoire saisie par la fiction », Le Débat, n 165, 2011

MALlaVAL Catherine, « Josée Dayan, 56 ans. Sa mère l'appelait 'mon petit Balzac, à cause de mon physique'. Elle revient avec Balzac sur TF1. Dame épique », Libération, 14 septembre 1999, http:// www.liberation.fr/portrait/1999/09/14/josee-dayan-56-ans-sa-mere-l-appelait-mon-petitbalzac-a-cause-de-mon-physique-elle-revient-avec-bal_283510, consulté le 6 mai 2016.

MAURY Louis, «Interview de Josée Dayan », Têtu, 2005, http://www.univers-l.com/

interview_josee_dayan.html consulté le 6 mai 2016.

MOMBERT Sarah, «Le cinéma de cape et d'épée ou la relève du panache ", in De l'Écrit à l'écran. Littératures populaires : mutations génériques, mutations médiatiques, éd. Jacques Migozzi, Limoges, PuLim, 2000, p. 467-478.

ROSENSTONE Robert A., « Like writing history with lighting : film historique/vérité historique », Vingtième Siècle, $n^{\circ}$ 46, 1995, p. 162-175.

RouchY Violette, La Reine Margot de Patrice Chéreau. Genèse et réalisation d'un film historique, Thèse de l'École Nationale des Chartes, Paris, 2006.

ROUCHY Violette, «Protestantisme et cinéma français », Bulletin de la Société de l'Histoire du Protestantisme Français, tome 154, avril-mai-juin, 2008, p. 157-285.

THOMSON Pauline, « La pop culture peut-elle remplacer les livres d'histoire ? ", Slate, $1^{\mathrm{er}}$ mars 2016, http://www.slate.fr/story/113585/pop-culture-contre-lavisse consulté le 15 mai 2016.

VEYRAT-MASSON Isabelle, Quand la télévision explore le temps. L'histoire au petit écran (1953-2000), Paris, Fayard, 2000.

VEYRAT-MASSON Isabelle, Télévision et histoire, la confusion des genres. Docudramas, docufictions et fictions du réel, Bruxelles, INA et de Boeck, 2008.

VEYRAT-MASSON Isabelle, « Au cœur de la télévision : l'histoire », Le Débat, n 177, 2013/5, p. 96-109.

\section{Les guerres de Religion : histoire, mémoire et représentations}

BOUCHER Jacqueline et Caroline ZUM KOLK, " Entretien avec Jacqueline Boucher ", $1^{\mathrm{er}}$ novembre 2012, http://cour-de-france.fr/article2580.html consulté le 26 avril 2016.

CARPI Olivia, Les guerres de Religion. Un conflit franco-français, Paris, Ellipses, 2012.

CROUZET Denis, Le haut cœur de Catherine de Médicis, Paris, Albin Michel, 2005.

EL KENZ David, « Le massacre de la Saint-Barthélemy est-il un lieu de mémoire victimaire (fin XVI ${ }^{\mathrm{e}}$ siècle-2009) ? », https://oratoiredulouvre.fr/documents/le-massacre-de-la-saint-barthelemy-estil-un-lieu-de-memoire-victimaire.php consulté le 12 mai 2016

GARRISSON Janine, « Deux vieilles France en échauguette, les guerres de Religion », Vingtième Siècle, $\mathrm{n}^{\circ}$ 5, 1985, p. 91-100.

GIRAULt Pierre-Gilles et Mathieu MERCIER (éds.), Fêtes et crimes à la Renaissance : la cour d'Henri III, Paris-Blois, 2010. 
JARRY Jacques, «Les guerres de Religion dans le roman français », Études de langue et de littérature françaises de l'Université de Hiroshima, $\mathrm{n}^{\circ}$ 1, 1991, p. 51-67.

JOUTARD Philippe et alii, La Saint-Barthélemy ou les résonances d'un massacre, Neufchâtel, Delachaux et Niestlé, 1976.

LE ROUX Nicolas, Les guerres de Religion, Paris, Belin, 2009.

MOMBERT Sarah, «Les frères ennemis du roman historique. Sur quelques romans des $\mathrm{XIX}^{\mathrm{e}}$ et $\mathrm{XX}^{\mathrm{e}}$ siècles consacrés aux guerres de religion ", Hommage à Marie-Thérèse Hipp, Travaux de littérature , tome X, Paris, Klincksieck, 1997, p. 281-293.

POURTEAU Roger, « La Saint-Barthélemy dans le roman populaire », https://oratoiredulouvre.fr/ articles/La-Saint-Barthelemy-dans-Les-Pardaillan-de \%20Michel-Zevaco.php consulté le 2 mai 2016.

VÉNARD Marc, «1685-1985. L'Édit de Nantes est révoqué », Revue d'Histoire de l'Église de France, tome $72, \mathrm{n}^{\circ} 188,1986, \mathrm{p} .123-143$.

WANEGFFELEN Thierry, Catherine de Médicis, le pouvoir au féminin, Paris, Payot, 2005.

Filmographie

Les guerres de Religion à l'écran

L'Assassinat du duc de Guise (Georges Hatot, 1897)

L'Assassinat du duc de Guise (RTF, $1^{\mathrm{e}}$ ch., 1960)

Le Chevalier de Pardaillan (Bernard Borderie, 1962)

Hardi! Pardaillan (Bernard Borderie, 1963)

Jean de la Tour Miracle (ORTF, $\left.1^{\mathrm{e}} \mathrm{ch} ., 1968\right)$ : extrait de l'épisode 1 de Jean de la Tour Miracle : www.ina.fr/video/CPF86623064/jean-de-la-tour-miracle-e10-haut-les-coeurs-et-vive-l-amourvideo.htm

L'Exécution du duc de Guise (ORTF, $2^{\mathrm{e}}$ ch., 1971)

La Dame de Monsoreau (ORTF, $2^{\mathrm{e}}$ ch., 1971) : Bande annonce de La Dame de Monsoreau : www.youtube.com/watch $? \mathrm{v}=8 \mathrm{KF} \_$WoyujzE.

Le Roi qui vient du Sud/Heinrich, der gute König (TF1, 1979)

Les Prisonnières (Antenne 2, 1985)

Catherine (Antenne 2,1986)

Le Chevalier de Pardaillan (Antenne 2,1988)

Catherine de Médicis (Antenne 2, 1989)

Saint-Germain ou la négociation (FR3, 2003)

Les Tudors (Showtime, 2007-2010)

L'assassinat d'Henri IV (FR2, 2009)

Henri 4 (France 2, 2010)

Les Borgias (Showtime, 2011-2013)

Borgia (Canal+, 2011-2014)

Autres œuvres citées 
Déchéance (Michel Zévaco, 1918)

Le Capitan (André Hunebelle, 1960)

Le Capitaine Fracasse (Pierre Gaspard-Huit, 1961)

Le Chevalier de Maison rouge (RTF, 1963)

Lagardère (ORTF, $1^{\mathrm{e}}$ ch., 1967)

D’Artagnan (ORTF, $2^{\mathrm{e}}$ ch., 1969-1970)

Le 16 à Kerbriant (ORTF, $1^{\mathrm{e}}$ ch., 1971)

Joseph Balsamo (ORTF, $1^{\mathrm{e}}$ ch., 1973)

Ardéchois, cœur fidèle (ORTF, $2^{\mathrm{e}}$ ch., 1974)

Le Comte de Monte Cristo (FR3, 1979-1980)

L'Epingle noire (Antenne 2, 1982)

Fabien de la Drôme (Antenne 2,1983)

Marianne, une étoile pour Napoléon (Antenne 2, 1983)

Des Grives aux loups (Antenne 2,1984)

Félicien Grevèche (Antenne 2,1986)

Le Gerfaut (TF1, 1987)

La Comtesse de Charny (TF1, 1989)

Le Chevalier de Pardaillec (Antenne 2, 1991, sketch des Inconnus) : https://www.youtube.com/ watch $? \mathrm{v}=$ biAUsaBKU3c

La Rivière Espérance (France 2, 1995)

Le Comte de Monte Cristo (TF1, 1998)

Les Misérables (TF1, 2000)

Les Liaisons dangereuses (TF1, 2003)

Les Rois maudits (France 2, 2005)

Rome (HBO, 2005-2007)

Spartacus (Starz, 2010-2013)

Vikings (History, depuis 2013)

Marco Polo (Netflix, depuis 2014)

Versailles (Canal+, depuis 2015)

\section{NOTES}

1. L'expression "guerres de Religion " ainsi orthographiée est une expression consacrée, forgée dans les années 1540 par les historiens allemands du XVI ${ }^{e}$ siècle pour désigner la guerre de la Ligue de Smalkade. L'expression est adoptée ensuite par analogie pour qualifier les affrontements religieux qui se sont déclenchés en France en 1562 et finalement passée dans la 
langue française, notamment dans le Dictionnaire universel d'Antoine de Furetière en 1690 pour caractériser un type spécifique de guerre civile.

2. Bertie et la rédaction de lexpress.fr, «Pour une bonne série historique, reprenez la recette des Feux de l'amour ! », post de blog mis en une sur L'Express.fr, http://www.lexpress.fr/culture/tele/ pour-une-bonne-serie-historique-reprenez-la-recette-des-feux-de-l-amour_1236203.html consulté le 16 avril 2016 ; Clara, "Étude de cas : le pouvoir de séduction des séries historiques ", post de blog sur SériesChéries, 29 novembre 2013, https://seriescheries.com/2013/11/29/lepouvoir-de-seduction-des-series-historiques/ consulté le 16 avril 2016.

3. Olivia Carpi, Les guerres de Religion. Un conflit franco-français, Paris, Ellipses, 2012.

4. Antoine de Baeque et Christian Delage dir., De l'histoire au cinéma, Bruxelles, Complexe, 1998.

5. Hervé Dumont, chapitre 10 «La France déchirée par les guerres de Religion », Encyclopédie du film historique [En ligne], volume 2 « Moyen Âge et Renaissance », , http://www.hervedumont.ch/ page.php?id=fr10\&idv=2\&idc=837 consulté le 16 avril 2016.

6. Claude Aziza, Guide de l'Antiquité imaginaire, roman, cinéma, bande dessinée, Paris, Les Belles lettres, 2008 ; Violette Rouchy, La Reine Margot de Patrice Chéreau. Genèse et réalisation d'un film historique, Thèse de l'École Nationale des Chartes, Paris, 2006 et «Protestantisme et cinéma français », Bulletin de la Société de l'Histoire du Protestantisme Français, tome 154, avril-mai-juin, 2008, p. 157-285 ; Nicolas Le Roux, "Sexe, violence et histoire. Un XVI ${ }^{\mathrm{e}}$ siècle de cinéma ", conférence du 18 janvier 2012 au séminaire FRAMESPA, Lieux de construction du rapport au passé (medias, fiction, internet), https://instruhist.hypotheses.org/249 consulté le 16 avril 2016.

7. On retiendra notamment : L'Assassinat du duc de Guise (RTF, $1^{\mathrm{e}}$ ch., 1960), dans la collection « La Caméra explore le temps » de Stello Lorenzi, André Castelot et Alain Decaux ; L'Exécution du duc de Guise (ORTF, 1971) ; Catherine de Médicis avec Alice Sapritch (Antenne 2, 1989) ; Saint-Germain ou la négociation de Gérard Corbiau (FR3, 2003) ; le docu-fiction de Jacques Malaterre sur l'assassinat d'Henri IV (FR2, 2009) ; Henri 4 de Jo Baier (France 2, 2010).

8. Marjolaine Boutet, Les Séries télé pour les nuls, Paris, Éditions First, 2009, p. 95.

9. Cf. par exemple : David Buxton, De «Bonanza » $a ̀$ «Miami vice», formes et idéologies dans les séries télévisées, La Garenne-Colombes, L’Espace européen, 1991 et Les séries télévisées. Formes, idéologie et mode de production, Paris, L'Harmattan, 2010 ; Éric Maigret et Guillaume Soulez dir., « Les raisons d'aimer les séries télé ", Mediamorphoses, hors série $\mathrm{n}^{\circ} 3$, janvier 2007, http:// documents.irevues.inist.fr/handle/2042/23356 consulté le 16 avril 2016 ; Delphine Dubs et Marie Quevreux «La philosophie des séries télévisées: un territoire à (ré)explorer ", Implications philosophiques, http://www.implications-philosophiques.org/semaines-thematiques/philosophiedes-series/la-philosophie-des-series-televisees-un-territoire-a-reexplorer-introduction/ consulté le 16 avril 2016.

10. Buxton, Les séries télévisées. Formes, idéologie et mode de production, Paris, L'Harmattan, 2010, p. 7 ; Alain Carrazé, Les séries télé. Toutes les clés, Paris, Hachette, 2007, p. 84 ; Jacques Baudou et Jean-Jacques Schleret, Les feuilletons historiques de la télévision française de Thierry la Fronde à Maria Vandamme, Paris, Huitième Art Éditions, 1992, p. 10-11.

11. Extrait de l'épisode 1 de Jean de la Tour Miracle : www.ina.fr/video/CPF86623064/jean-de-latour-miracle-e10-haut-les-coeurs-et-vive-l-amour-video.html; Bande annonce de La Dame de Monsoreau : www.youtube.com/watch ?v=8KF_WoyujzE.

12. Merci à Estelle Caron, déléguée régionale INA Nord pour son accueil et pour m'avoir autorisée à publier certaines images et extraits de la série. A l'heure où nous écrivons la série n'est pas disponible sur le nouveau service de vidéos à la demande Ina Premium lancé le 30 septembre 2015.

13. Jacques Baudou et Jean-Jacques Schleret, Les feuilletons historiques de la télévision française de Thierry la Fronde à Maria Vandamme, Paris, Huitième art éditions, 1992, p. 200 : «Quasi absence de scènes extérieures, décors interchangeables, scènes bâclées, anachronismes, duels sans aucun dynamisme, une interprétation qui frise le ridicule »; Cinéma \& Histoire/Histoire \& Cinéma, «La 
saga des Pardaillan de Michel Zévaco », www.hervedumont.ch : «ce feuilleton est une nouvelle occasion ratée de rendre enfin justice à Michel Zévaco et à son fameux bretteur, plutôt malmené au cinéma (...), une commande de bas de gamme en vidéo, bâclée sans imagination ni rythme (...) Quant aux comédiens, ils font du Grand-Guignol ».

14. Claude Aziza, « Le cas Alexandre Dumas ", L'Histoire, $n^{\circ} 226,1998$, p. 28.

15. Michel Zévaco, Les Pardaillan, Robert Laffont, Paris, 1988 (2 tomes).

16. Matthieu Letourneux, «Bibliothèque des grandes aventures. Michel Zévaco", http:// mletourneux.free.fr/ consulté le 16 avril 2016 ; Aline Demars, Michel Zévaco et le roman feuilleton, thèse pour le doctorat d'Etat ès lettres, Paris-IV-Sorbonne, 1985, «Les romans modernes de Michel Zévaco», Romantisme, $\mathrm{n}^{\circ}$ 53, 1986, p. 107-122, "La Saint-Barthélémy dans Les Pardaillan », Cahiers de l'Imaginaire, numéro spécial Zévaco, 1987, et Préface à Michel Zévaco, Les Pardaillan, Paris, Robert Laffont, coll. «Bouquins ", 1988 ; ROUDIER Luce, Michel Zévaco : écrire l'Histoire, Mémoire de Master I Théorie de la Littérature, ENS/EHESS, sous la direction de Judith Lyon-Caen, 2014, La Fabrique Zévaco. Manufacture de l'écriture, Mémoire de Master II Théorie de la Littérature, ENS/EHESS, sous la direction de Judith Lyon-Caen, 2015, "Michel Zévaco, entre histoire romancée et anarchie historique », in Ecrire l'histoire avec des " si », éd. Florian Besson et Jan Synowiecki, Paris, Editions de la rue d'Ulm, 2015, p. 39-47, "Roman populaire et désengagement : la violence politique désactivée chez Michel Zévaco », Le Rocambole, $\mathrm{n}^{\circ}$ 73, 2015, p. 101-111.

17. Brigitte Krulic, Fascination du roman historique: intrigues, images et femmes fatales, Paris, Autrement, 2007, p. 5.

18. Annabel Audureau, «Étude des couvertures de la série des Fantômas dessinées par Gino Starace entre 1911 et 1913 ", Belphégor. Littératures populaires et culture médiatique, 11/1, 2013, https://belphegor.revues.org/110 consulté le 16 avril 2016.

19. Patrice Caillot, "Zévaco cinéaste ", Les Cahiers de la Cinémathèque, $\mathrm{n}^{\circ} 28,1979$, p. 215-218 ; Demars (1988), p. 131 ; Claude Aziza, «Romanciers : le goût du sang », L'Histoire, Hors Série n 17, 2002 , p. 87.

20. Matthieu Letourneux, "Bibliothèque des grandes aventures. Michel Zévaco - Eléments biographiques », http://mletourneux.free.fr/ consulté le 16 avril 2016 , p. 2.

21. www.michelzevaco.com

22. Ibid., « Michel Zévaco. Adaptations à l'écran », p. 5. Cette période fut notamment marquée par le succès de Lagardère (ORTF, $1^{\mathrm{e}}$ ch., 1967), incarné par Jean Piat, une mini-série qui a tellement bien fonctionné que Jean-Pierre Decourt l'a remontée en deux parties pour le cinéma, ce qui a donné Le Bossu et Les Aventures de Lagardère (1968), dans le même esprit que Le Capitaine Fracasse (1961) de Pierre Gaspard-Huit.

23. Hervé Dumont, « La saga des Pardaillan de Michel Zévaco », Cinéma et Histoire, op. cit., p. 3.

24. Sarah Mombert, «Le cinéma de cape et d'épée ou la relève du panache », in De l'Écrit à l'écran. Littératures populaires: mutations génériques, mutations médiatiques, dir. Jacques Migozzi, Limoges, PuLim, 2000, p. 467-478.

25. Régine Chaniac, «La fiction en série : évolution de la programmation en France », Quaderni, $\mathrm{n}$ -9, hiver 1989-90, p. 44.

26. Stéphane Benassi, Séries et feuilletons TV. Pour une typologie des fictions télévisuelles, Liège, Éditions du CEFAL, 2000, p. 9, 36 ;

27. Marjolaine Boutet, "Soixante ans d'histoire des séries télévisées américaines", Revue de recherche en civilisation américaine, $\mathrm{n}^{\circ} 2,2010$, https://rrca.revues.org/248 consulté le 26 avril 2016.

28. Boutet (2009), p. 91 et « Depuis quand les Français sont-ils accros aux séries TV ? ", Inaglobal, 24 avril 2014 [mis à jour 17 avril 2015], http://www.inaglobal.fr/television/article/depuis-quandles-francais-sont-ils-accros-aux-series-tv-7551, consulté le 16 avril 2016. 
29. Carrazé, p. 83-85; Baudou et Schleret, p. 10-11.

30. Boutet (2009), p. 92 et Boutet (2014); Chaniac, p. 47.

31. Isabelle Veyrat-Masson, Quand la télévision explore le temps. L'histoire au petit écran (1953-2000), Paris, Fayard, 2000, p. 357-364, 372-375.

32. Ibid., p. 372-374.

33. Baudou et Schleret, p. 11 ; Veyrat-Masson, p. 374.

34. Chaniac, p. 48, 51-52.

35. Baudou et Schleret, p. 12.

36. Ibid., p. 200.

37. Carrazé, p. 83.

38. Les guerres de Religion posent toutefois moins de problèmes mémoriels que d'autres conflits franco-français, comme l'Occupation en particulier, cf. Isabelle Veyrat-Masson, « Au cœur de la télévision : l'histoire ", Le Débat, n 177, 2013/5, p. 96, 99 et Télévision et histoire, la confusion des genres. Docudramas, docufictions et fictions du réel, Bruxelles, INA et de Boeck, 2008. Page?

39. Benassi, p. 21 et 139.

40. Veyrat-Masson (2000), p. 131.

41. Sarah Mombert, "Les frères ennemis du roman historique. Sur quelques romans des $\mathrm{XIX}^{\mathrm{e}}$ et $\mathrm{XX}^{\mathrm{e}}$ siècles consacrés aux guerres de religion ", Travaux de littérature, tome X, Paris, Klincksieck, 1997, p. 467- 293 ; Denis Diderot, Essai sur les règnes de Claude et de Néron, Euvres de Denis Diderot, J.A. Naigeon éd., tome 9, Paris, 1798, p. 149.

42. Jacques Jarry, "Les guerres de Religion dans le roman français ", Études de langue et de littérature françaises de l'Université de Hiroshima, n 1, 1991, p. 51.

43. Buxton (2010), p. 9

44. Chaniac, p. 54.

45. Veyrat-Masson (2000), p. 135

46. Veyrat-Masson, (2013), p. 98 et Veyrat-Masson (2000), p. 206 et suivantes.

47. Buxton, p. 17

48. Marjolaine Boutet, «Les séries télévisées américaines des années 1980. Une autre histoire de la guerre du Vietnam ", Vingtième Siècle, n 84, hiver 2004, p. 61-73, https://www.cairn.info/ revue-vingtieme-siecle-revue-d-histoire-2004-4-page-61.htm consulté le 15 mai 2016.

49. Baudou et Schleret, p. 200.

50. Krulic, p. 35, 51.

51. Hormis ces deux indications, la chronologie des guerres de Religion se révèle assez évanescente et erronée dans la série puisque c'est à Chartres et non à Blois qu'Henri III trouve refuge après les barricades parisiennes de mai 1588 et c'est en 1593 , non en 1588 , que se déroule la procession de la Ligue, qui n'a pas pour objet de porter des doléances au roi, comme cela est dit dans la série (épisode 11), mais de galvaniser la combativité des Parisiens révoltés et assiégés par Henri IV.

52. Roger Pourteau, «La Saint-Barthélemy dans le roman populaire », https:// oratoiredulouvre.fr/articles/La-Saint-Barthelemy-dans-Les-Pardaillan-de \%20Michel-Zevaco.php consulté le 2 mai 2016.

53. Krulic, p. 16.

54. Voir par exemple la décoration néo-Renaissance du château de Blois, restauré par un disciple de Viollet-Le-Duc. Le lieu fut visité par Hugo, Balzac et Dumas et abondamment représenté dans la peinture d'histoire du XIX ${ }^{\mathrm{e}}$ siècle.

55. Baudou et Schleret, p. 199.

56. Il n'est sans doute pas anodin que Les Inconnus aient intitulé leur parodie des séries historiques françaises des années 1980 «Le chevalier de Pardaillec ", diffusé le 28 octobre 1991 sur Antenne 2 et visible ici : https://www.youtube.com/watch ?v =biAUsaBKU3c 57. Ibid. 
58. Robert A. Rosenstone, «Like writing history with lighting: film historique/vérité historique ", Vingtième Siècle, n 46, 1995, p. 162-175.

59. Buxton, Les séries télévisées, formes, idéologie..., p. 14.

60. Baudou et Schleret, p. 200.

61. L'Ecole des Annales domine alors le champ de la recherche universitaire depuis l'entre-deuxguerres, privilégiant les problématiques économiques et sociales. Ce n'est qu'à partir des années 1980 précisément que se développe de nouveau en France une histoire religieuse et politique, s'intéressant notamment à l'étude des mentalités et des modes de vie.

62. A cause notamment de sa publication en 1981 par l'atelier des thèses de l'université de Lille en 4 volumes et non par une maison d'édition commerciale, ce qui est venu plus tard, en 1986, chez Ouest France, dans une version compactée, Jacqueline Boucher et Caroline zum Kolk, «Entretien avec Jacqueline Boucher», $1^{\text {er }}$ novembre 2012, http://cour-de-france.fr/ article2580.html consulté le 26 avril 2016.

63. Krulic, p. 12, 24 et 36.

64. Aline Demars, préface à Les Pardaillan de Michel Zévaco, Paris, Robert Laffont, 1988, p. 128.

65. René Garguilo, «Un genre majeur de la littérature populaire : le roman de cape et d'épée », Roman populaire et/ou roman historique, Monográfico de l'Ull Critic 4-5, 1999, p. 85-103; Janine Garrisson, Préface de La Reine Margot d'Alexandre Dumas, Paris, Gallimard, 2009, p. 12.

66. Michel Zévaco, Les Pardaillan, Paris, Robert Laffont, 1988, p. 265-266.

67. Ibid., p. 277.

68. Ibid., p. 228.

69. Baxton, p. 14 ; Bénassi, p. 21.

70. Krulic, p. 10

71. Ibid., p. 56

72. Ibid., p. 199.

73. Janine Garrisson, «Deux vieilles France en échauguette, les guerres de Religion », Vingtième Siècle, $n^{\circ} 5,1985$, p. 91 ; Philippe Joutard et alii, La Saint-Barthélemy ou les résonnances d'un massacre, Neufchâtel, 1976, p. 221 sq.

74. Éliane Viennot, «De la Reine Marguerite à La Reine Margot: les lectures de l'histoire d'Alexandre Dumas ", L'École des Lettres, n 13-14, 1994, www.elianeviennot.fr/Articles/ViennotMgV-Dumas-histoire.pdf, consulté le 16 avril 2016.

75. Nicolas Le Roux, Les guerres de Religion, Paris, Belin, 2009, p. 517-539.

76. David El Kenz, « Le massacre de la Saint-Barthélemy est-il un lieu de mémoire victimaire (fin $\mathrm{XVI}^{\mathrm{e}} \quad$ siècle-2009)?», https://oratoiredulouvre.fr/documents/le-massacre-de-la-saintbarthelemy-est-il-un-lieu-de-memoire-victimaire.php consulté le 12 mai 2016; Marc Vénard, «1685-1985. L'Édit de Nantes est révoqué », Revue d'Histoire de l'Église de France, tome 72, n 188, 1986, p. 123-143.

77. Veyrat-Masson (2000), p. 372.

78. Veyrat-Masson (2013), p. 98.

79. Ibid., p. 103.

80. Jacques Migozzi dir., De l'écrit à l'écran. Littératures populaires: mutations génériques, mutations génétiques, Limoges, Pulim, 2000. Pages?

81. Garrisson (2009), p. 17.

82. Éliane Viennot, «Le corps signifiant des souverains dans La Reine Margot d'Alexandre Dumas », Jean-Marie Roulin, dir., Corps, littérature, société, 1789-1900, Saint-Étienne, 2005, www.elianeviennot.fr/Articles/Viennot-MgV-Dumas-corps.pdf, p. 3.

83. Joutard, p. 123.

84. Ibid.

85. Thierry Wanegffelen, Catherine de Médicis, le pouvoir au féminin, Paris, Payot, 2005 ; Denis Crouzet, Le haut cour de Catherine de Médicis, Paris, Albin Michel, 2005. 
86. Éliane Viennot, Postface de La Reine Margot d'Alexandre Dumas, Paris, Livre de Poche, 1994, www.elianeviennot.fr/Articles/Viennot-MgV-postface-Dumas.pdf, p. 1 ; Krulic, p. 40, 171.

87. Le Roux (2009), p. 489-499.

88. Joutard, p. 126.

89. Pierre-Gilles Girault et Mathieu Mercier dir., Fêtes et crimes à la Renaissance : la cour d'Henri III, Paris-Blois, 2010 ; Pierre de l'Estoile, Journal des choses mémorables advenues durant tout le règne de Henri III, Cologne, 1720, vol. 1, p. 102.

90. Viennot, De la Reine..., et Postface; Garrisson, Préface, p. 8.

91. Viennot, De la Reine..., p. 13.

92. Krulic, p. 17, 144 .

93. Ibid., p. 146, 199 ; Mombert (1997), p. 467.

94. Les historiens, anglo-saxons notamment, parlent de " première modernité » pour désigner les XVIe, XVII et XVIIIe siècles, afin de contrebalancer l'impression négative de caducité et d'immobilisme que donne l'expression « Ancien Régime » souvent employée pour qualifier cette période à partir du XIX ${ }^{\mathrm{e}}$ siècle.

95. Krulic, p. 19, 20, 26, 199, 203.

96. Joutard, p. 127-128

97. Le Roux (2009), p. 500-514.

98. Loïc Artiaga (dir.), Le roman populaire. Des premiers feuilletons aux adaptations télévisées, Paris, Autrement, 2008, p. 92 ; Krulic, p. 177-182.

99. Jean-Jacques Rousseau, Du Contrat social, Essai de philosophie politique, Paris, Flammarion, 2011 [1762].

100. Honoré de Balzac, La Comédie Humaine, Paris, Gallimard, «La Pléiade », 1976 - 1981 (tomes 2 à 12 , publiés originellement entre 1829 et 1850 ).

101. Friedrich Nietzsche, Humain trop humain, Paris, Le Livre de Poche, 1995 [1878].

102. Demars (1988), p. 2.

103. Ibid.

104. Ibid.

105. Vittorio Frigerio, «Bons, belles et méchants (sans oublier les autres » : le roman populaire et ses héros », Le roman populaire, op. cit., p. 100-110.

106. Demars (1988), p. 102.

107. Ibid., p. 121.

108. Ibid., p. 25 sq.

109. Viennot, op.cit., p. 3.

110. Frigerio, op.cit., p. 113.

111. Catherine Mallaval, "Josée Dayan, 56 ans. Sa mère l'appelait 'mon petit Balzac, à cause de mon physique'. Elle revient avec Balzac sur TF1. Dame épique ", Libération, 14 septembre 1999, http://www.liberation.fr/portrait/1999/09/14/josee-dayan-56-ans-sa-mere-l-appelait-monpetit-balzac-a-cause-de-mon-physique-elle-revient-avec-bal_283510, consulté le 6 mai 2016.

112. Louis Maury, «Interview de Josée Dayan», Têtu, 2005, http://www.univers-l.com/ interview_josee_dayan.html consulté le 6 mai 2016.

113. Entretien avec Josée Dayan réalisé par Christophe Kechroud-Gibassier pour France 2, version 2005, http://www.cinemotions.com/interview/3438 consulté le 6 mai 2016.

114. Mallaval, art.cit.

115. Buxton (2010), p. 15.

116. Baudou et Schleret, p. 11.

117. Boutet, (2004) p. 62.

118. Buxton (2010), p. 17-18.

119. Pascale Goetschel, "Compte-Rendu de Quand la télévision explore le temps... », Vingtième Siècle, vol. $72, n^{\circ} 1,2001$, p. 163. 
120. Krulic, p. 19-20

121. Veyrat-Masson (2013), p. 97.

122. François Cuisset, La décennie. Le grand cauchemar des années 1980, Paris, La Découverte, 2006.

123. Krulic, p. 14-16.

124. Joutard, p. 131

125. Martine Jaubert, Sylvie Lalagüe-Dulac et Brigitte Louichon, «Les fictions historiques : un objet littéraire, éditorial et scolaire qui interroge les frontières ", Repères, $n^{\circ}$ 48, 2013, p. 7-16.

126. Veyrat-Masson (2000), p. 398-404.

127. Pierre Nora et alii, «L'histoire saisie par la fiction», Le Débat, $\mathrm{n}^{\circ} 165,2011$; Pauline Thomson, «La pop culture peut-elle remplacer les livres d'histoire?», Slate, $1^{\mathrm{er}}$ mars 2016, http://www.slate.fr/story/113585/pop-culture-contre-lavisse consulté le 15 mai 2016.

\section{RÉSUMÉS}

Cet article se propose d'analyser la forme et le fond d'une production télévisuelle méconnue car déjà ancienne (1986-88) et considérée comme très inférieure à d'autres du même genre qui l'ont précédée, celles de l'âge d'or du feuilleton historique télévisé, dans les années 1960-70. Car cette adaptation, très fidèle, du roman de cape et d'épée de Michel Zévaco est indéniablement porteuse d'un imaginaire, qui n'a d'ailleurs rien de spécifique, des guerres de Religion françaises du XVI siècle. Celles-ci ont effectivement alimenté une véritable «mythologie nationale", dont on retrouve l'essentiel dans cette œuvre télévisuelle qui se voulait plaisante et consensuelle, mais dont le contenu est pourtant loin d'être anodin, idéologiquement parlant.

This article analyses the form and content of a little-known French television series produced and broacast between 1986 and 1988. Le Chevalier de Pardaillan is considered today to be inferior in quality to period dramas from the 1960s and the 1970s, labelled as a "golden age " for French period dramas. This rather faithful adaptation of a voluminous "cape and dagger » novel by Michel Zévaco is undeniably the vehicle of broader cultural fantasies of sixteenth century French religious wars. Indeed, these wars helped to nurture what can be called a "national mythology.» Le Chevalier de Pardaillan, in appearance a pleasant and consensus-seeking TV series, is in fact ideologically oriented and a typical contribution to the popularization of this specific national mythology.

\section{INDEX}

Keywords : period drama, France, 16th century, cape and dagger genre, religious wars, stereotype, national mythology, politically correct, 1980s

Mots-clés : feuilleton, France, série historique, roman de cape et d'épée, guerres de Religion, stéréotype, roman national, 16ème siècle, politiquement correct, années 1980 


\section{AUTEUR}

\section{OLIVIA CARPI}

Olivia CARPI, maître de conférences en histoire moderne à l'Université de Picardie-Jules Verne, dont les travaux de recherche portent sur les guerres de Religion françaises du XVI ${ }^{\mathrm{e}}$ siècle, en particulier sur la Ligue et le processus de pacification du conflit civil sous l'angle de l'histoire municipale ; auteure de : Une République imaginaire. Amiens durant les troubles de religion, Paris, Belin, 2005 et Les guerres de Religion (1559-1598). Un conflit franco-français, Paris, Ellipses, 2012. Olivia CARPI is an associate professsor of modern history at the University of Picardie Jules Verne ; her research focuses on sixteenth century French religious wars, in particular the "Ligue » and the process of civil pacification studied from the angle of municipal history. She is the author of : Une République imaginaire. Amiens durant les troubles de religion, Paris, Belin, 2005 and Les guerres de Religion (1559-1598). Un conflit franco-français, Paris, Ellipses, 2012. 